\title{
Softdesk Energy: \\ A Case Study in Early \\ Design Tool Integration
}

\author{
RECEIVED \\ APR 271998 \\ OSTI
}

\section{Krishnan Gowri, David P. Chassin and Michele Friedrich}

distribution of thIS document is UNLMmte fo MASTER

PNNL-11851 


\section{DISCLAIMER}

This report was prepared as an account of work sponsored by an agency of the United States Government. Neither the United States Government nor any agency thereof, nor any of their employees, makes any warranty, express or implied, or assumes any legal liability or responsibility for the accuracy, completeness, or usefulness of any information, apparatus, product, or process disclosed, or represents that its use would not infringe privately owned rights. Reference herein to any specific commercial product, process, or service by trade name, trademark, manufacturer, or otherwise does not necessarily constitute or imply its endorsement, recommendation, or favoring by the United States Government or any agency thereof. The views and opinions of authors expressed herein do not necessarily state or reflect those of the United States Government or any agency thereof. 


\section{DISCLAIMER}

Portions of this document may be illegible electronic image products. Images are produced from the best available original document. 


\title{
Softdesk Energy: A Case Study in Early Design Tool Integration
}

\author{
Krishnan Gowri, David P. Chassin and Michele Friedrich \\ Pacific Northwest National Laboratory(a) \\ Richland, WA 99352
}

\begin{abstract}
Softdesk Energy is a design tool that integrates building energy analysis capability into a highly automated production drafting environment (AutoCAD and Softdesk AutoArchitect). This tool provides users of computer aided design/drafting (CAD) software the opportunity to evaluate the energy impact of design decisions much earlier in the design process than previously possible with energy analysis software. The authors review the technical challenges of integrating analytic methods into design tools, the opportunities such integrated tools create for building designers, and a usage scenario from the perspective of a current user of Softdesk Energy. A comparison between the simplified calculations in Softdesk Energy and detailed simulations using DOE-2 energy analysis is made to evaluate the applicability of the Softdesk Energy approach. As a unique example of integrating design and drafting, Softdesk Energy provides an opportunity to study the strengths and weaknesses of integrated design tools and gives some insight into the future direction of the CAD software towards meeting the needs of diverse design disciplines.
\end{abstract}

(a) Pacific Northwest National Laboratory is operated for the U.S. Department of Energy by Battelle Memorial Institute under contract DE-AC06-76RLO 1830. 
$\underline{\text { Introduction }}$

Conservative estimates, based on building energy performance research, indicate that at least $15 \%$ of the energy now used in new buildings could be saved, at no additional first cost, if energy-efficient features currently available had been incorporated in the original design. Further, when energy efficiency is not adequately considered during design, a building's operating costs are higher over its 50- to 75-year lifetime. Despite significant advances in building technology and tighter building codes, buildings in the U.S. consume $\$ 200$ billion/year. Half of this energy is wasted if one considers the cost-effective measures now available during design and operation of buildings [1].

Decisions on building geometry, orientation, space planning, envelope and occupancy made at the schematic design stage have a significant impact on the energy performance of buildings. And at this stage the designer's limited information is inadequate for detailed energy analysis. Because of time constraints and the lack of appropriate tools, energy evaluation is often delayed until the detailed design phase, when it is too late and too expensive to change the basic decisions. Hence, it is critical to evaluate energy impacts at the schematic design stage. Because CAD tools are widely used for drafting the floor plans, there exists a valuable opportunity to assist designers by embedding energy evaluation tools in the $\mathrm{CAD}$ environment. Such an approach will make the energy analysis process transparent and allows the designer to concentrate on comparing design alternatives and on performing "what if" scenarios for improving energy performance of a building.

Softdesk Energy [2] is the result of a decade of research and development aimed at developing integrated design tools for improving energy performance as part of the Advanced Energy Design and Operation Technologies (AEDOT) project [3]. The AEDOT prototype 1, developed using workstation technologies, demonstrated the feasibility of sharing data and knowledge among drafting and design tools. In an effort to widely disseminate this concept, a commercial drafting environment developed by Autodesk, Incorporated was chosen. Softdesk Energy was developed through a collaborative effort between the US Department of Energy, the University of Oregon, and Softdesk, Inc., developers of AutoArchitect [4], a widely used architectural add-on for AutoCAD [5]. 
$\underline{\text { Integrated Building Design }}$

Recent trends in computer-aided building design (CABD) research are toward the development of integrated systems that provide support to diverse disciplines throughout the entire building life cycle. Integrated systems aim to enhance design quality and productivity, and minimize the communication barriers that exist between disciplines. Figure 1 shows an example of an integrated design environment, in which the various building subsystems are identified by domain expertise and interlinked to develop the building project. Typically, architects; structural, mechanical and electrical engineers; contractors and estimators work together in generating the detailed design of a building. Each professional involved in the process has a specific view of the building data for their design/analysis task. For example, a floor plan generated by an architect will be used by the (i) structural engineer to design the structural system, (ii) mechanical engineer to design the heating, ventilating and air-conditioning (HVAC) systems and to layout the distribution ducts, and (iii) electrical engineer to develop the wiring plan.

Many research prototype software systems have been developed to demonstrate the feasibility and potential for integrated building design. Integrated building design environment (IBDE) developed by Fenves et al. [6] focuses on the representation and communication of design information. Intelligent computer-aided design system (ICADS) by Pohl et al. [7] demonstrates the integration of drafting and design knowledge to provide expert advice to designers. A knowledge-based design support environment (KNODES) by Rutherford and Maver [8] shows the integration of a large number of design tools for distributed problem solving. Several other research efforts are presently underway to explore and solve various problems in integrated design [e.g., 9, 10]. One common theme emerging from all these research prototypes is to utilize artificial intelligence techniques to represent symbolic knowledge and numerical data for early design support and sharing/reusability of design data.

Though research prototypes have significantly advanced the understanding of integration issues, they have failed to provide a methodology or tool that can be deployed in design practice. User interfaces and development platforms have been the major issues prohibiting the practical use and commercialization of research prototypes. In architectural design practice, computers are widely used for drafting. Architectural drawings convey a wealth of information that often needs to be extracted 
manually for design analysis. If the design analysis tools were available within the drafting environment, then they could provide valuable support to designers in the early stages of design.

To be effective, design tools used during preliminary design should be capable of (i) providing intelligent default values for data that need to be ascertained, (ii) performing a quick and easy approach to design analysis, and (iii) dynamically exchanging data with the drafting environment. These three issues are critical for successful deployment of integrated building design tools.

\section{Integrating $\mathrm{CAD}$ and Energy Analysis}

Energy analysis is undertaken by the mechanical engineer to size the HVAC equipment and design the air distribution systems. The advantages of exploring effective solutions by altering building orientation, envelope thermal characteristics, window-to-wall ratio, etc. have been based generally on designer's experience and heuristics. Traditionally, energy evaluation has not been a priority in building design. But there exists a great potential to achieve an energy-efficient building, if energy analysis is integrated with drafting during the preliminary design stage.

The challenge in integrating $\mathrm{CAD}$ and energy analysis has three important aspects: (i) user interaction, (ii) data exchange and (iii) calculation methods. User interaction in a CAD system can be in several forms, from using a digitizer and mouse to pull down menus to keyboard commands. Typically the user draws points, lines, arcs and text to generate an architectural drawing. The data for each drawing entity is stored in a database using a format specific to the CAD system. This data consists of the coordinates for start point, end point, line type and other parameters relevant to the drawing entity. For energy analysis purposes, these drawing entities must be pieced together to identify physical building objects such as walls, windows and doors. This can be accomplished with a pre-defined library of building objects and using a geometry interpreter that can extract the appropriate building geometry data required for analysis. Each building envelope object and its associated thermal characteristic must be specified for calculating the energy demand on the heating or cooling system (loads). It is possible to set default thermal properties based on a construction type corresponding to each object and to allow the user to edit this information through dialog windows. In addition to the geometry of the building, the location of the building, design temperatures and internal heat gains need to be known before performing the analysis. 
Energy analysis methods have evolved over the past two decades from empirical estimates to detailed hourly energy load calculations. Simultaneously a large number of energy analysis software tools have been developed [11]. All available energy analysis methods fall into one of the following three categories: (i) heuristic estimates, (ii) daily/weekly/monthly bin calculations, and (iii) hourly simulation. The amount of data required and accuracy of results varies depending on the assumptions and nature of analysis techniques used by each method. To be practical during the preliminary design stage, the analysis technique must be reliable but should not impose severe restrictions on data input or analysis execution time. During early design stages, the primary objective of analysis is to facilitate comparison of the various design alternatives and make quick decisions to revise geometry or select appropriate materials. Hence, simplified bin method calculations are sufficient for early design support. It will allow the user to evaluate the impact of thermal resistance of envelope components, building geometry and internal heat gains (e.g., computers, lights, people). -

\section{Softdesk Energy Features}

Softesk Energy integrates energy analysis capability within a commercially available drafting environment using a geometry interpreter to automatically extract building geometry data from $\mathrm{CAD}$ drawings. Figure 2 shows a schematic of the interaction between the CAD system and energy load calculation module. The user interacts primarily with the CAD system to generate the floor plan and to specify the building thermal parameters. The geometry interpreter processes all the drawing entities and objects to determine the total floor area, exterior wall, window, door and roof areas. This geometry data is added to the energy database that will provide all the necessary input for the energy calculation module. In addition to the geometry data, the user needs to specify the location of building, occupancy and internal heat gains (e.g., occupants, lights, computers, and refrigerators). This information can either be set using approximate defaults or specified interactively using menus and clialog windows.

Auto $C A D$ and Softdesk AutoArchitect provide the underlying $C A D$ environment for implementing Softdesk Energy. An energy icon and sub-menu are added to the drafting menu, so the user can access energy data, interpret geometry and perform energy load calculations at any time while drawing the floor plan. Softdesk Energy classifies the user input in to two categories: essential and 
extended input data. The essential category consists of (i) building location, (ii) building type (e.g. office, residential, industrial) and (iii) orientation. The extended category includes (i) envelope thermal properties; (ii) schedules for people, lighting and equipment; (iii) thermostat setting and (iv) ventilation rate. While the user must specify the essential input data before performing energy analysis, the extended input data can be left as defaults or modified as needed.

The building location and building type information can be used to obtain default values for all the detailed input required for analysis. For example, the user can specify the location of the building and retrieve all the climate data including winter/summer design temperatures, relative humidity and solar radiation from a weather database. After retrieving the climate data, the user is provided an option to review and modify this data. This feature allows users to customize a weather database for certain microclimates and also enables the user to update/maintain the database. In Softdesk Energy, the building type input encompasses defaults for all data items in the extended input category. Residential and commercial building types are provided with typical defaults representing most common construction types and building characteristics. The user can create a new building type such as "Industrial" or "Office" by specifying the construction types of envelope components, number of occupants, schedule and power for lights and equipment, winter and summer indoor thermostat settings and ventilation rates. During a particular analysis, if the user needs to modify an extended category input (e.g., ventilation rate), it can be accessed directly from the menu. Often the extended category input data must be obtained from a large body of manufacturer's literature or design handbooks. The approach of combining defaults according to building type minimizes userinput requirements without compromising the flexibility for data modification. The user interface provides graphical icons and intuitive dialogs for specifying the input. For example, US and Canada maps are available to the user to select the location; bio-climatic charts are provided to review the climate data; sliders can be used for specifying the occupancy schedules; etc. Figure 3 shows the US map display that provides the user the opportunity to specify the building location and an option to review/modify the associated climate data.

Once the floor plan is drawn and the essential input data are specified, the user can perform the energy analysis. The energy analysis process starts with the geometry interpreter translating the drawing data for exterior wall, window and roof objects. The interpreter scans the building's perimeter and creates a list of surfaces that define the geometry of the zone (heated and cooled space). On each surface, the interpreter identifies walls, glazing and doors. If a roof or a floor is not 
drawn, the interpreter automatically creates them based on the area of top and ground floors. If a problem is encountered, such as an incomplete perimeter, the interpreter will determine if the problem is fatal. If not fatal, it will alert the user of potential inaccuracies in geometry data. If the problem is fatal, the interpreter will identify and circle the area on the drawing where the error occurred and zoom in to show the details of the problem. If the interpreter succeeds it will add the envelope component area and orientation data to the energy database. Then the energy load calculation module can be activated to graph the energy profile.

The energy load calculation in Softdesk Energy is based on the Simplified Energy Analysis Method (SEAM) developed by the American Society of Heating, Ventilating and Air Conditioning Inc., (ASHRAE) [11]. The current SEAM implementation provides feed back on the energy loads of the building and not on the energy performance of HVAC systems. The energy load calculation includes internal gain from lights, people, equipment, solar radiation and heat gain; building envelope heat transmission and loss; ventilation heat gain and loss; and thermal mass effects. Softdesk Energy assumes that the entire building has uniform interior thermal conditions and can be characterized as a single zone. This assumption simplifies input requirements and avoids the complicated calculation methods associated with multiple HVAC control points, heat transfer between various zones and operating schedules. Energy use for a building is calculated for January and July, the peak heating and cooling months. The model then linearly interpolates between these extreme loads to represent all intermediate conditions throughout the year. This methodology does not account for variations in the solar gains and other non-temperature weather parameters throughout the year, which do not have a linear relationship between the two extremes. SEAM calculations are implemented as an external program. Softdesk Energy calculates all the load components (e.g., transmission, solar, internal, ventilation) and displays them separately as a stacked bar chart. This presentation allows the user to evaluate the impact of changing particular building thermal properties or other building parameters. It is important to note that energy load components displayed by Softdesk Energy can not be used for sizing HVAC systems.

\section{Case Study Example}

Softdesk Energy has been available to the architectural design community since June 1995. Softdesk has distributed more than 10000 copies of the software along with AutoArchitect during 1995-96. 
Typically designers have used Softdesk Energy to compare the choice of building envelope components and thermal properties. This section presents a case study based on a building renovation project in which an engineer used Softdesk Energy to determine the thermal resistance of envelope components and to demonstrate compliance to the state energy code requirements. The building is a single-story convenient store located in Albany, New York. Figure 4 shows the CAD model of the building layout drawn using AutoCAD and AutoArchitect. Data used to perform energy calculation in Softdesk Energy originate from three sources. The first is user input; the second is geometry acquired from the drawing; and the third is default values provided within the software.

The following three "what-if" scenarios were analyzed using Softdesk Energy to study the impact of envelope thermal resistance, window area and lighting power density:

Scenario 1: Insulation - Increase thermal resistance of exterior wall sheathings from $\mathrm{R}-6$ to $\mathrm{R}-10$, and roof insulation from $\mathrm{R}-30$ to $\mathrm{R}-45$.

Scenario 2: Windows - Increase glazing area from 120 sq.ft to 240 sq.ft by adding windows to the west and north walls.

Scenario 3: Lighting - Decrease lighting power from $3.3 \mathrm{~W} / \mathrm{sq} . \mathrm{ft}$ to $2.3 \mathrm{~W} / \mathrm{sq} . \mathrm{ft}$.

Softdesk Energy calculations provide average winter and summer loads expressed in Btu/sq.ft of the conditioned floor area. Figure 5 shows graphically the winter and summer loads for the above three scenarios in comparison to the base case. Increasing the exterior wall insulation thermal resistance of envelope decreases the winter heating load by $2.1 \mathrm{Btu} / \mathrm{sq}$. $\mathrm{ft}$ and decreases the summer cooling load by $0.4 \mathrm{Btu} / \mathrm{sq} . \mathrm{ft}$. Increasing the glazing area results in significantly higher heating and cooling loads. Decreasing the connected lighting power lowers the cooling load, but increases the heating load by more than twice, because of the lower internal heat gain.

To assess the trend of variation in loads predicted by Softdesk Energy, detailed analysis of the above three scenarios were simulated using DOE-2.1E [13]. The DOE-2.1E model closely represented the Softdesk Energy input. The DOE-2.1E model differed from the Softdesk model in the following ways: 1) the floor was modeled with a $U$-value of $0.12 \mathrm{Btu} / \mathrm{hr}-\mathrm{ft}{ }^{2} .^{\circ} \mathrm{F}$ in the DOE-2.1E model and as a slab with R-S vertical insulation in the Softdesk model; 2) The inside temperature for DOE2 calculations was $72^{\circ} \mathrm{F}$ at all times, Softdesk was $65^{\circ} \mathrm{F}$ in winter and $78^{\circ} \mathrm{F}$ in summer; 3) output from 
DOE2.1E is monthly loads (Btu). The loads were divided by the number of hours in the month and the building square footage $\left(1289.8 \mathrm{ft}^{2}\right)$ for comparison with Softdesk Energy.

Table 1 shows a summary of winter and summer loads by component calculated by DOE-2.1E and Softdesk Energy. Softdesk Energy calculations for occupant loads, equipment loads, lighting loads and infiltration loads remain the same for all cases, whereas DOE-2.1E shows some variation in these loads for each case. This can be attributed to the fact that Softdesk Energy calculations do not consider interactions between loads, whereas DOE-2.1E simulation includes algorithms to consider such phenomenon. Though the winter-opaque surface conduction loads are comparable, there exist significant differences between the models in calculating the winter/summer solar gain and glazing conduction, and summer opaque conduction load. This may be due to the SEAM cooling load calculation method adapted for Softdesk Energy, which does not adequately represent the thermal effects of glazing and solar radiation.

Figure 6 shows the total loads calculated by. Softesk Energy and DOE-2.1E are reasonably close and the trend of variation in loads between the scenarios is very similar. Figure 7 shows the percentage of change in loads from the base case for each of the three alternative scenarios considered. DOE-2.1E simulations show that increasing the insulation levels result in an $80 \%$ reduction in winter heating loads and an $1 \%$ reduction in summer cooling load from the base case loads. However, Softdesk Energy calculations show a $75 \%$ reduction in winter heating loads and a $3 \%$ reduction in summer cooling loads. In the case of increased window area, DOE-2.1E and Softdesk Energy loads differ by $14 \%$ for winter heating loads. Softdesk Energy results tend to be rather conservative, and the user is warned that increasing glazing area could result in severe penalty for winter heating loads. The DOE-2.IE results show a significantly lower penalty possibly because of the cooling load calculation algorithm and the lack of system interactions model in Softdesk Energy. In the third scenario the change in connected lighting power provides identical variation from base case loads for both DOE2. IE and Softdesk Energy. From the above comparisons, it can be concluded that Softdesk Energy provides sufficiently accurate information to compare and evaluate energy-efficiency measures at preliminary design stages. 


\section{Future Trend in Integrated Design Tools}

The CAD industry has recognized the critical need to support data sharing among the various design disciplines and the various stages during the life of a building. This has been a significant change in philosophy for software developers pre-occupied with data exchange between different $\mathrm{CAD}$ systems. Industry Alliance for Interoperability, a group of CAD and building industry experts, has developed a common object data model known as industry foundation classes (IFC) [14]. IFC aims to become a universal language for improving the communication, productivity, delivery time, cost, and quality throughout the design, construction, operation and maintenance life cycle of buildings. It is expected that CAD software, design tools and other applications such as estimating and costing will all interact through a central database created using the IFC model. Several CAD systems and software applications supporting the IFC model are currently being developed.

\section{Conclusion}

Softdesk Energy demonstrates the reality of integrating CAD and analysis tools to assist designers during the preliminary design stages. The feedback from industry users of Softdesk Energy show that significant productivity improvements and energy efficiency can be achieved with such integrated design tools. Though Softdesk Energy results as such can not be used for sizing HVAC systems, these results are found comparable to DOE-2.1E for predicting the trends in heating and cooling loads for design alternatives. Thus Softdesk Energy's integration strategy is ideally suited as a design decision-making tool for architects and engineers during the preliminary design stage. Recent developments in industry foundation classes for the architectural and civil engineering $C A D$ systems and object oriented paradigm provide a great opportunity for integrating more sophisticated analysis tools to be linked to CAD systems. 


\section{References}

1. Lawrence Berkeley National Laboratory. "Assuring Building Performance: Creating BLISS," Center for Building-Science News, Berkeley, California, Summer 1995.

2. Softdesk Energy: User's Manual, Softdesk Inc., Henniker, New Hampshire, 1995.

3. Brambley, M.R., Crawley, D.B., Hostetler, D.D., Stratton, R.C., Addison, M.S., Deringer, J.J., Hall, J.D., and Selkowitz, S.E., "Advanced Energy Design and Operation Technologies Research", Pacific Northwest Laboratories, Report No. PNL-6255, Richland, Washington, 1988.

4. Softdesk Version 7.5, Softdesk Inc., Henniker, New Hampshire, 1996.

5. User's Guide: AuroCAD Release 13, Autodesk Inc., Sausalito, California, 1994.

6. Fenves, S.J., Flemming, U., Hendrickson, C., and Maher, M.L., "Performance Evaluation in an Integrated Software Environment for Building Design and Construction Planning," Evaluating and Predicting Design Performance, John Wiley \& Sons, Inc., New York, 1992.

7. Pohl, J., Myers, L., and Chapman, A., "ICADS: An Intelligent Computer-Aided Design Environment," ASHRAE Transactions, Part 2, Atlanta, Georgia, 1990.

8. Rutherford, J.H., and Maver, T.W., "Knowledge-Based Design Support," Journal of Automation in Construction, Vol. 3, pp. 123-133, 1994.

9. Flemming, U., and Woodbury, R., "Software Environment to Support Early Phases in Building Design (SEED): Overview," Journal of Architectural Engineering, Vol. 1, pp. 147-152, 1995.

10. Papamichael, K.M., et al., "New Tools for the Analysis and Design of Building Envelopes," Thermal Performance of Exterior Envelopes of Buildings VI, Clearwater, Florida, 1995.

11. Amistadi, H., "CAD-Building Load Software Review," Engineered Systems, pp. 50-56, June 1995.

12. American Society of Heating, Refrigeration and Air-conditioning Engineers Inc., $A S H R A E$ Fundamentals, Atlanta, Georgia, 1989.

13. Lawrence Berkeley Laboratory, "DOE-2 Supplement, Version 2.IE," LBL-8706, National Technical Information Service, Springfield, Virginia, 1993.

14. International Alliance for Interoperability, Industry Foundation Classes - Release 1.0, Four Volumes, Washington, D.C., 1997. 


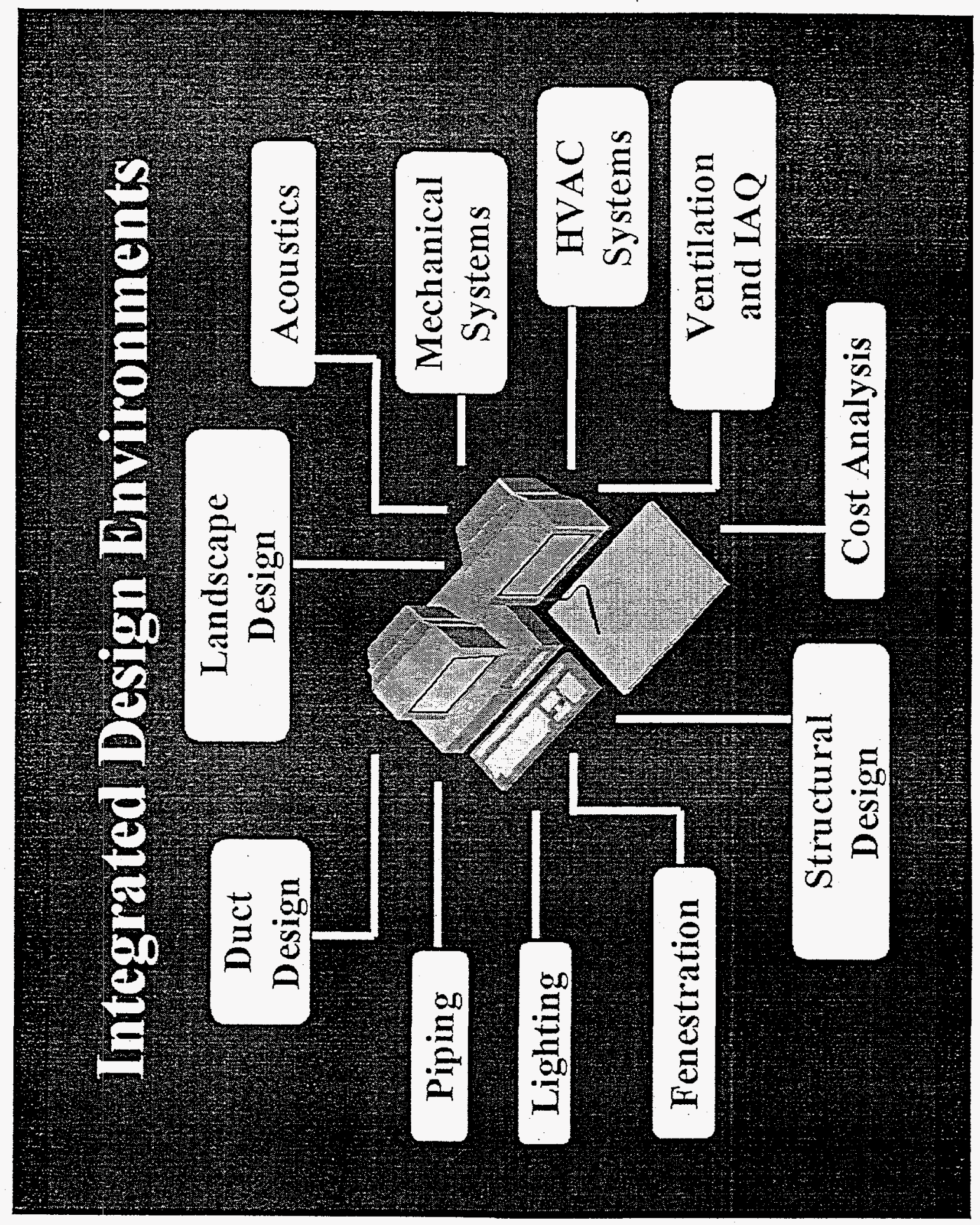

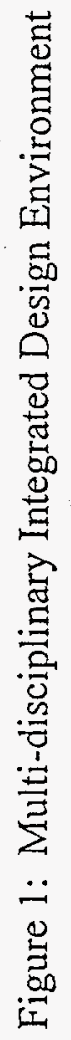




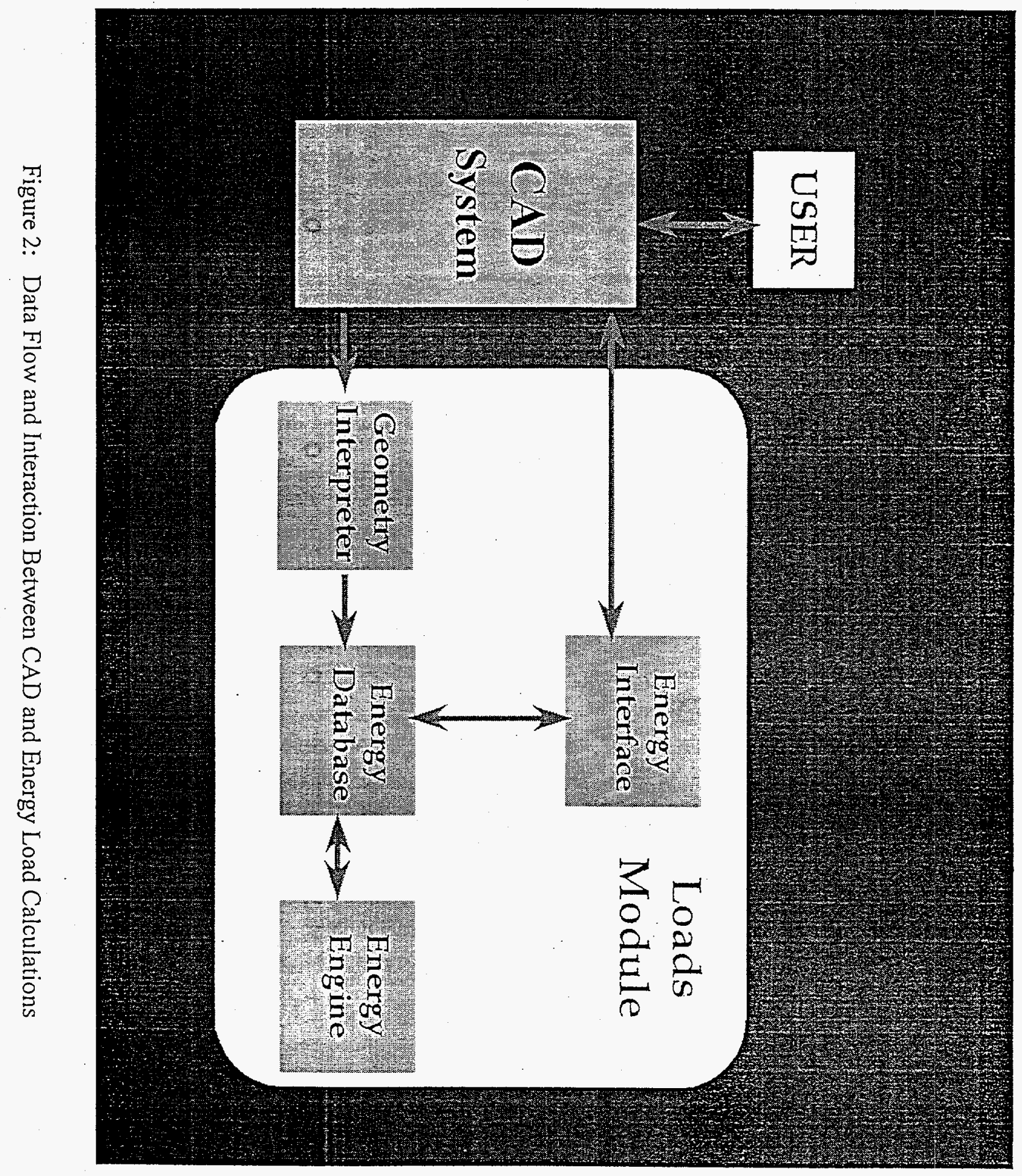




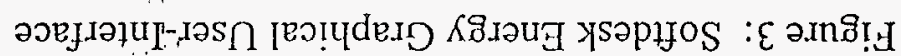

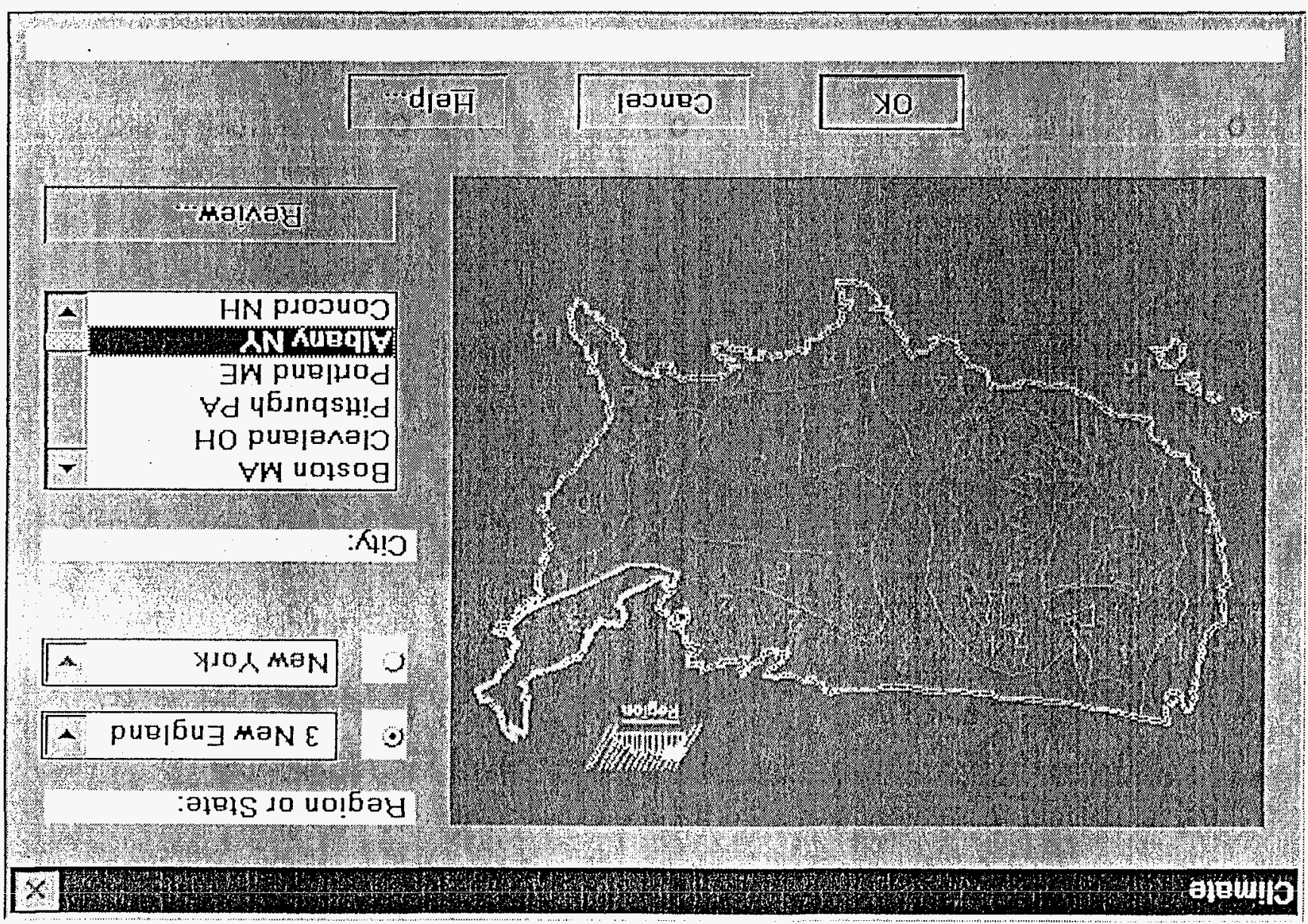




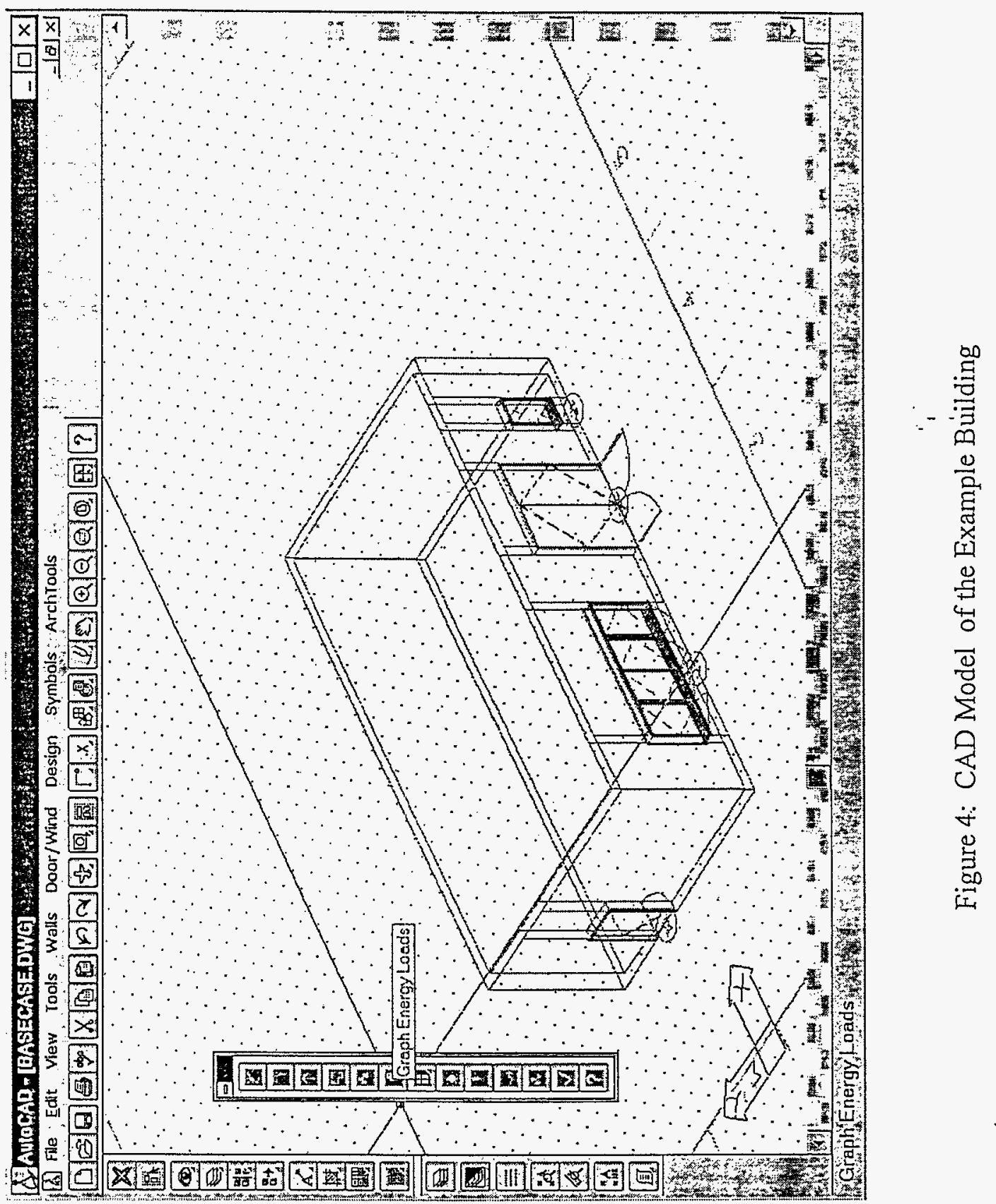




\section{Figure 5: Softdesk Energy Loads Summary}

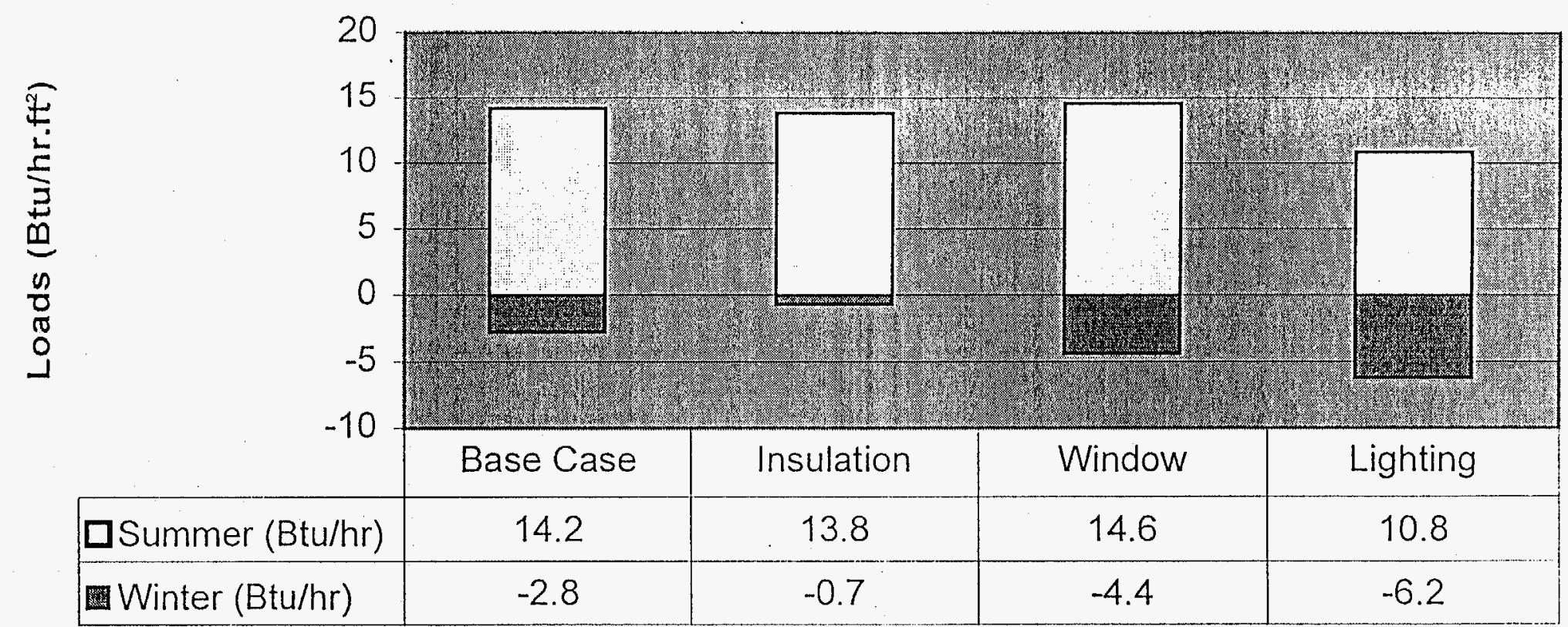

Figure 5: Softdesk Energy Loads Summary 


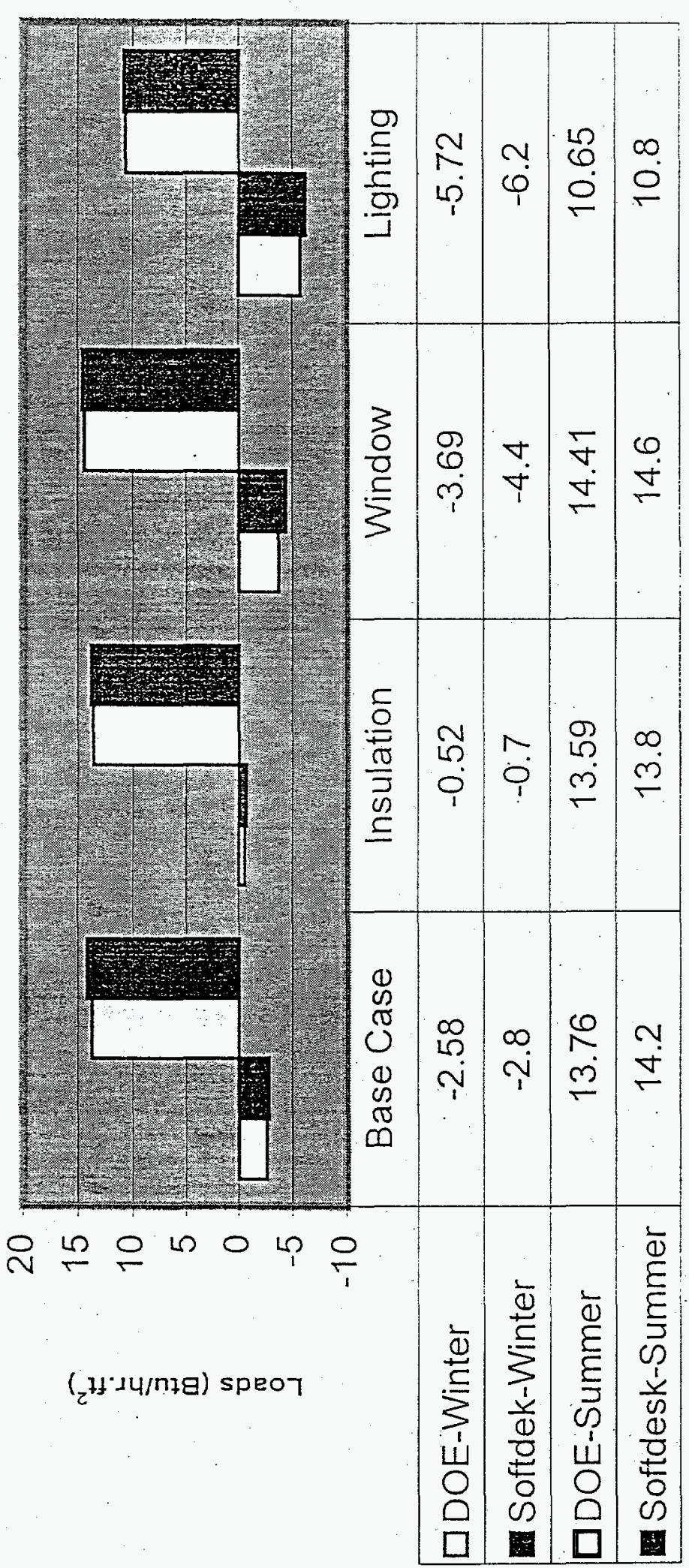

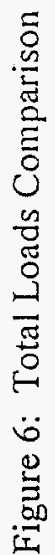




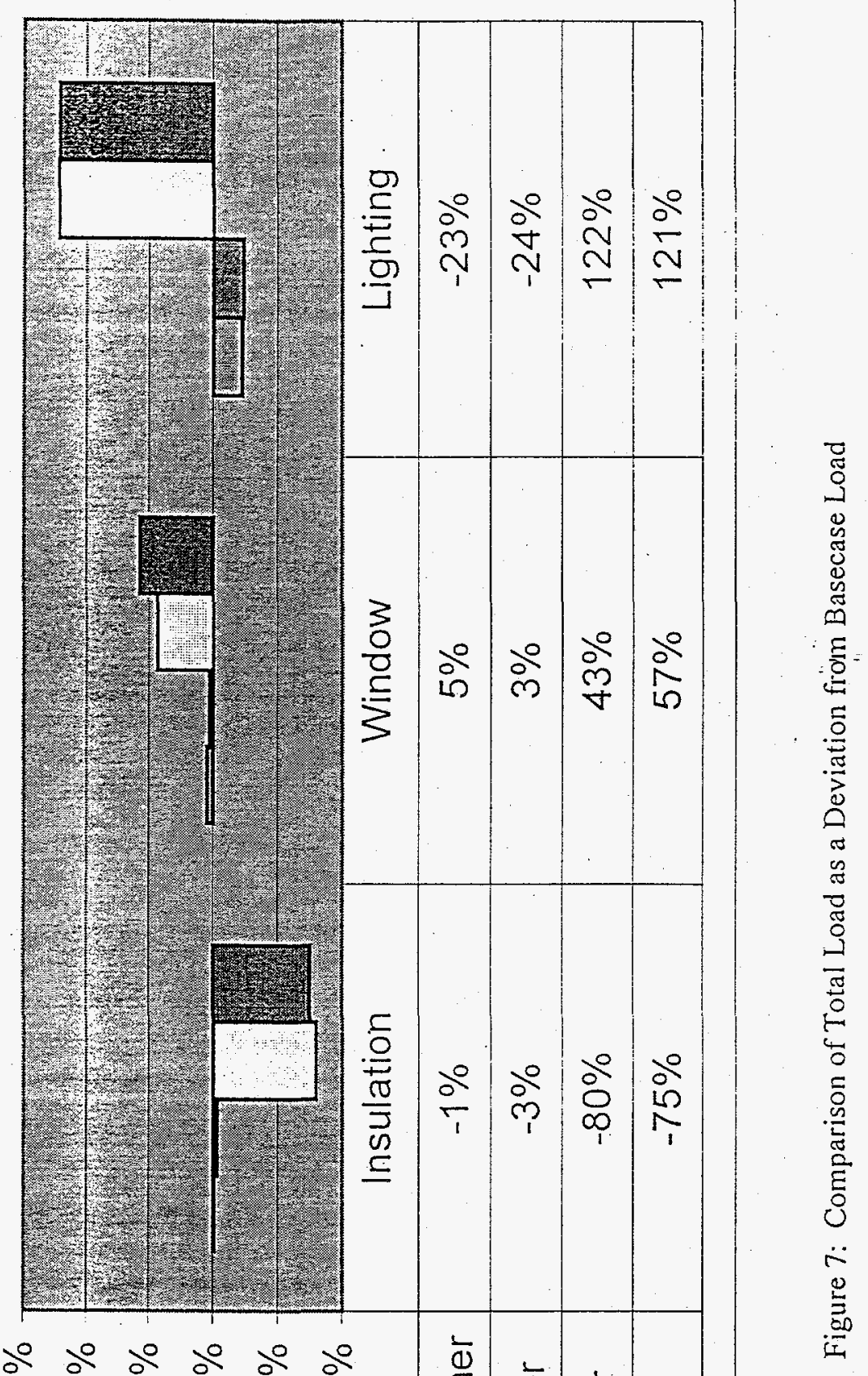

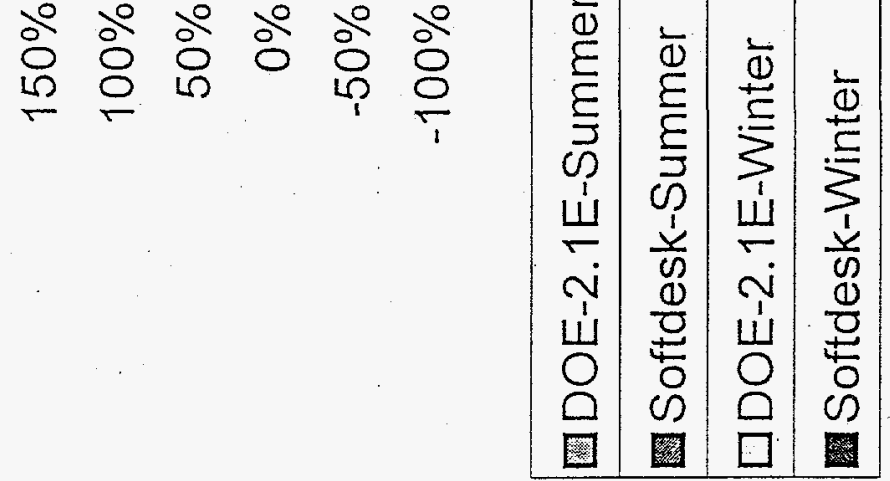


Table 1: Summary of Loads (Btu/hr. $\mathrm{ft}^{2}$ ) Calculated by Softdesk Energy and DOE 2.1E

\begin{tabular}{|c|c|c|c|c|c|c|c|c|}
\hline & \multicolumn{2}{|c|}{ Base Case } & \multicolumn{2}{|c|}{ Insulation } & \multicolumn{2}{|c|}{ Window } & \multicolumn{2}{|c|}{ Lighting } \\
\hline Winter & DOE-2.1E & Softdesk & DOE-2.1E & Softdesk & DOE-2.1E & Softdesk & DOE-2.1E & Softdesk \\
\hline Solar gain & 0.81 & 0.70 & 0.82 & 0.60 & 1.06 & 0.90 & 0.81 & 0.70 \\
\hline Opaque surface conduction & -10.03 & -10.00 & -8.14 & -7.80 & -9.62 & -9.70 & -10.03 & -10.00 \\
\hline Glazing conduction & -1.67 & -3.40 & -1.70 & -3.40 & -3.34 & -5.50 & -1.67 & -3.40 \\
\hline Occupant load & 0.26 & 0.40 & 0.29 & 0.40 & 0.24 & 0.40 & 0.24 & 0.40 \\
\hline Equipment load & 0.78 & 1.00 & 0.79 & 1.00 & 0.77 & 1.00 & 0.77 & 1.00 \\
\hline Lighting load & 10.27 & 11.20 & 10.42 & 11.20 & 10.19 & 11.20 & 7.16 & 7.80 \\
\hline Infiltration load & -3.00 & -2.70 & -3.00 & -2.70 & -2.99 & -2.70 & -3.00 & -2.70 \\
\hline Total & -2.58 & -2.80 & -0.52 & -0.70 & -3.69 & -4.40 & -5.72 & -6.20 \\
\hline Summer & & & & & & 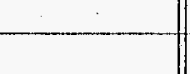 & & \\
\hline Solar gain & 0.69 & 1.40 & 0.71 & 1.10 & 1.55 & 1.70 & 0.69 & 1.40 \\
\hline Opaque surface conduction & 0.90 & 0.20 & 0.55 & 0.10 & 0.83 & 0.20 & 0.90 & 0.20 \\
\hline Glazing conduction & -0.06 & 0.00 & -0.06 & 0.00 & -0.11 & 0.10 & -0.06 & 0.00 \\
\hline Occupant load & 0.40 & 0.40 & 0.40 & 0.40 & 0.40 & 0.40 & 0.40 & 0.40 \\
\hline Equipment load & 0.78 & 1.00 & 0.79 & 1.00 & 0.77 & 1.00 & 0.78 & 1.00 \\
\hline Lighting load & 10.27 & 11.20 & 10.42 & 11.20 & 10.19 & 11.20 & 7.16 & 7.80 \\
\hline Infiltration load & 0.78 & 0.00 & 0.78 & 0.00 & 0.78 & 0.00 & 0.78 & 0.00 \\
\hline Total & 13.76 & 14.20 & 13.59 & $13.80 \|$ & 14.41 & 14.60 & 10.65 & 10.80 \\
\hline
\end{tabular}




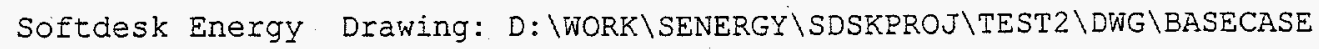

Summary for building (continued)

* Reff includes solar effects

Page 3

$05 / 15 / 1997 \quad 17: 28$ 


\section{Winter}

Average load for design month

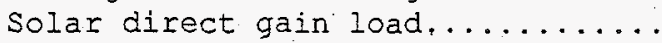

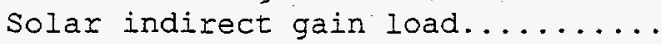

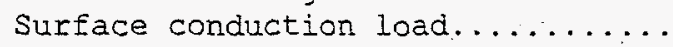

Glazing conduction load............

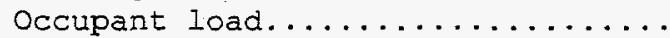

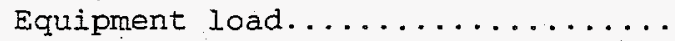

Lighting load. . . . . . . . . . . .

Ventilation load...............

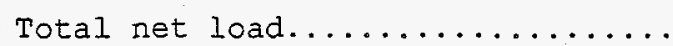

$0.2 \mathrm{Btu} / \mathrm{sf.h}$

$0.5 \mathrm{Btu} / \mathrm{sf.h}$

$-10 \mathrm{Btu} / \mathrm{sf.h}$

$-3.4 \mathrm{Btu} / \mathrm{sf.h}$

$0.4 \mathrm{Btu} / \mathrm{sf.h}$

I Btu/sf.h

$11.2 \mathrm{Btu} / \mathrm{sf} . \mathrm{h}$

$-2.7 \mathrm{Btu} / \mathrm{sf} . \mathrm{h}$

$-2.8 \mathrm{Btu} / \mathrm{sf} . \mathrm{h}$

\section{Summer}

Average load for design month

Solar direct gain load............

Solar indirect gain load...........

Surface conduction load...........

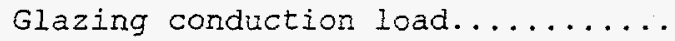

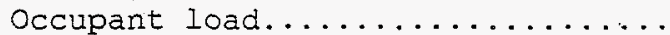

Equipment load.

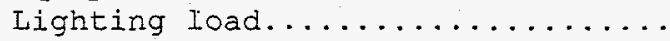

Ventilation load................

Total net load..............
$0.4 \mathrm{Btu} / \mathrm{sf} . \mathrm{h}$

$0.9 \mathrm{Btu} / \mathrm{sE}: \mathrm{h}$

$0.1 \mathrm{Btu} / \mathrm{sf} . \mathrm{h}$

$\sim 0$ Btu/sf.h

$0.4 \mathrm{Btu} / \mathrm{sf.h}$

$1 \mathrm{Btu} / \mathrm{sfih}$

11.2 Btu/sf.h

o Btu/sf.h

$14.1 \mathrm{Btu} / \mathrm{sf.h}$

\section{LOADS INEORMATION - BUILDING ELEMENTS}

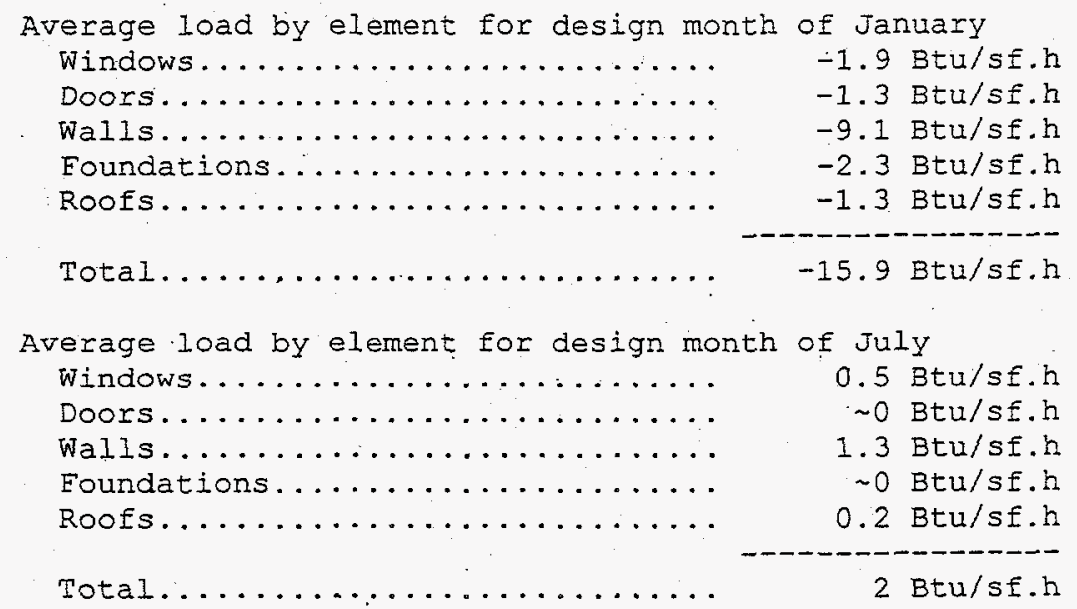




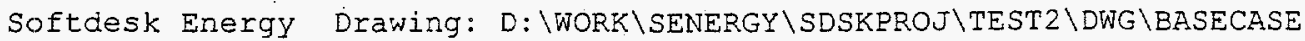

APPENDIX A - LOADS BY BUILDING ELEMENT

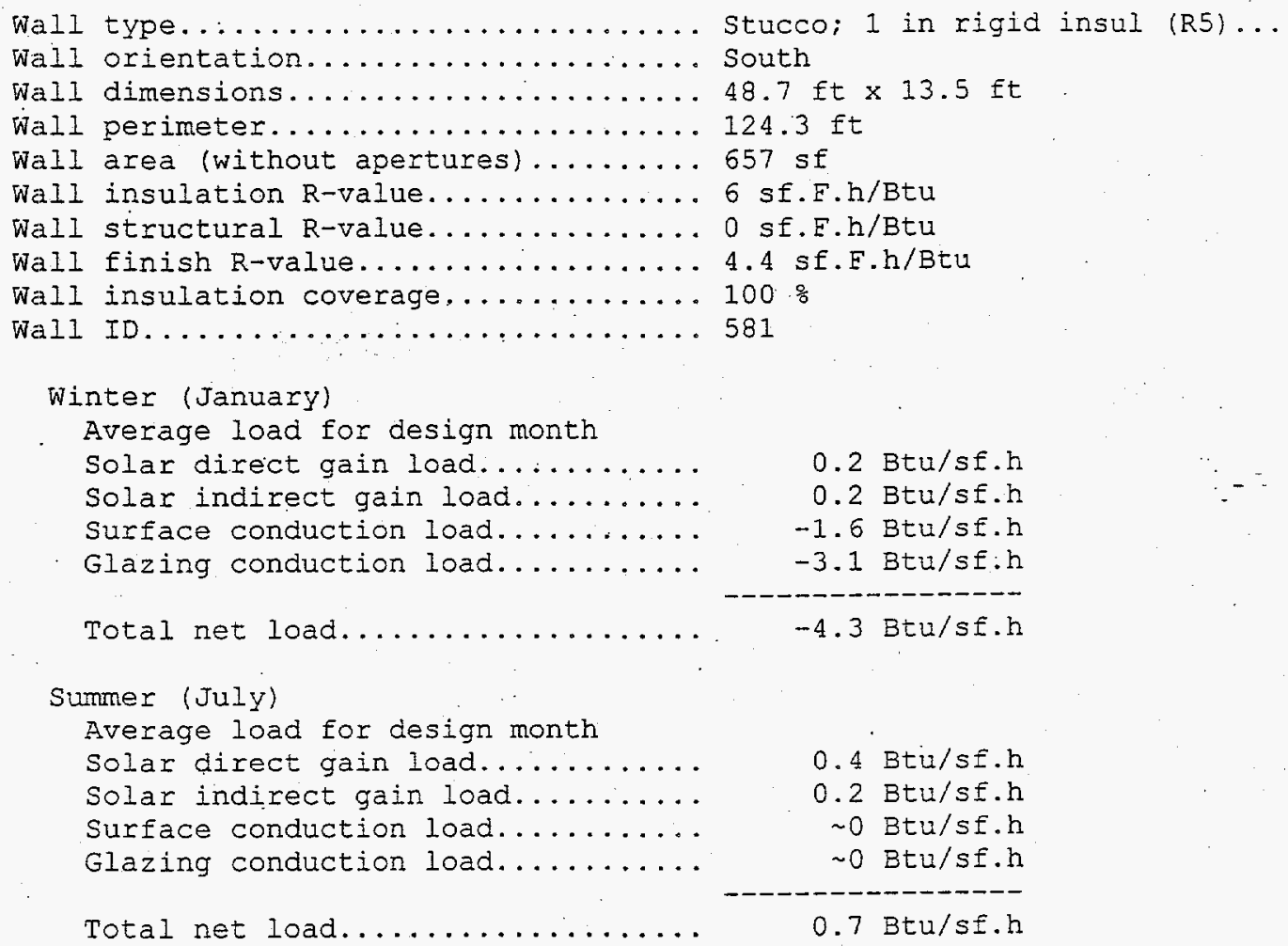




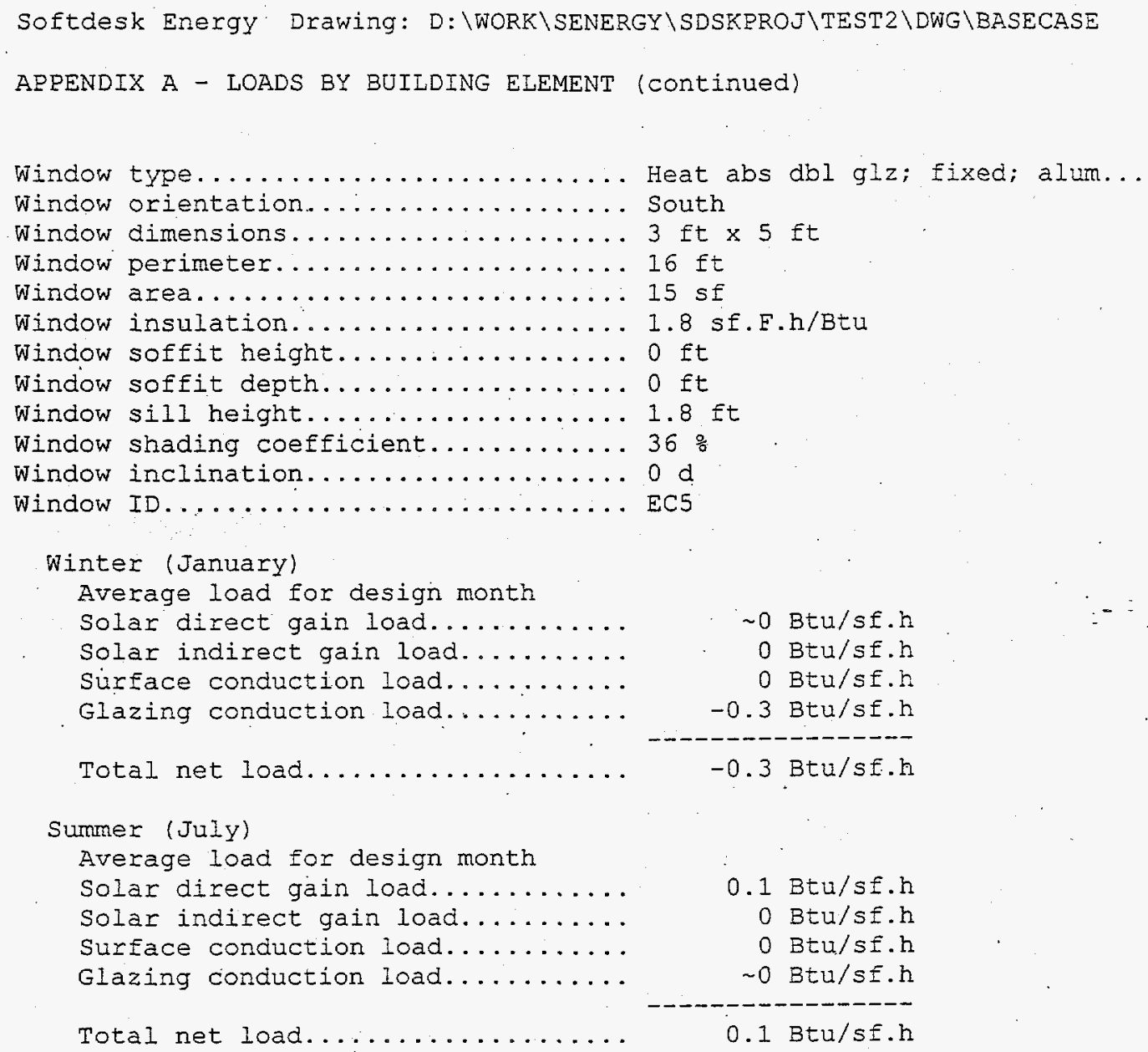




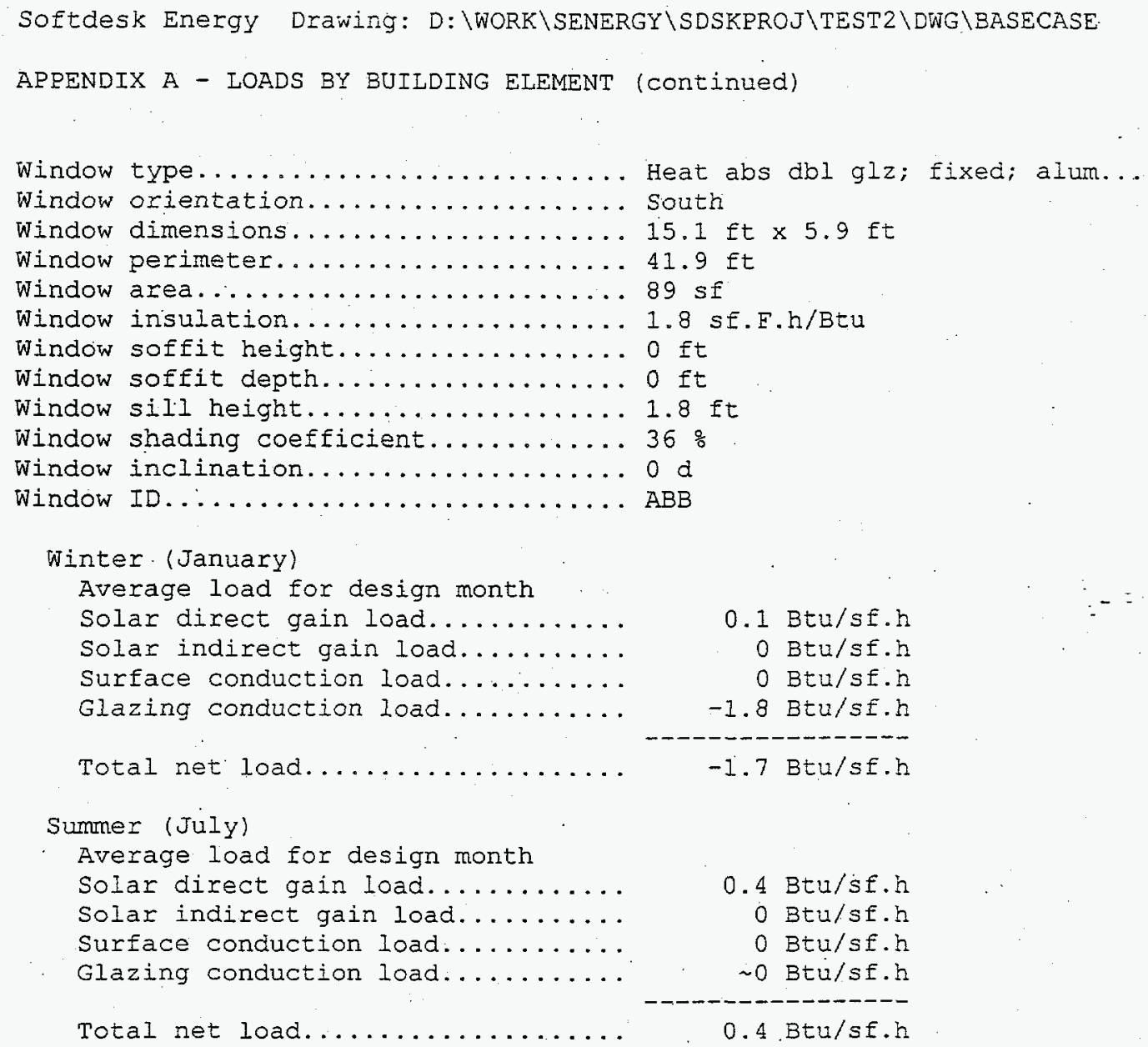




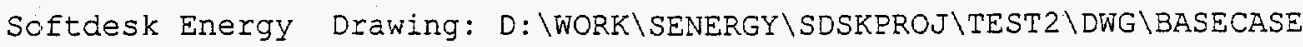

APPENDIX A - LOADS BY BUILDING ELEMENT (continued)

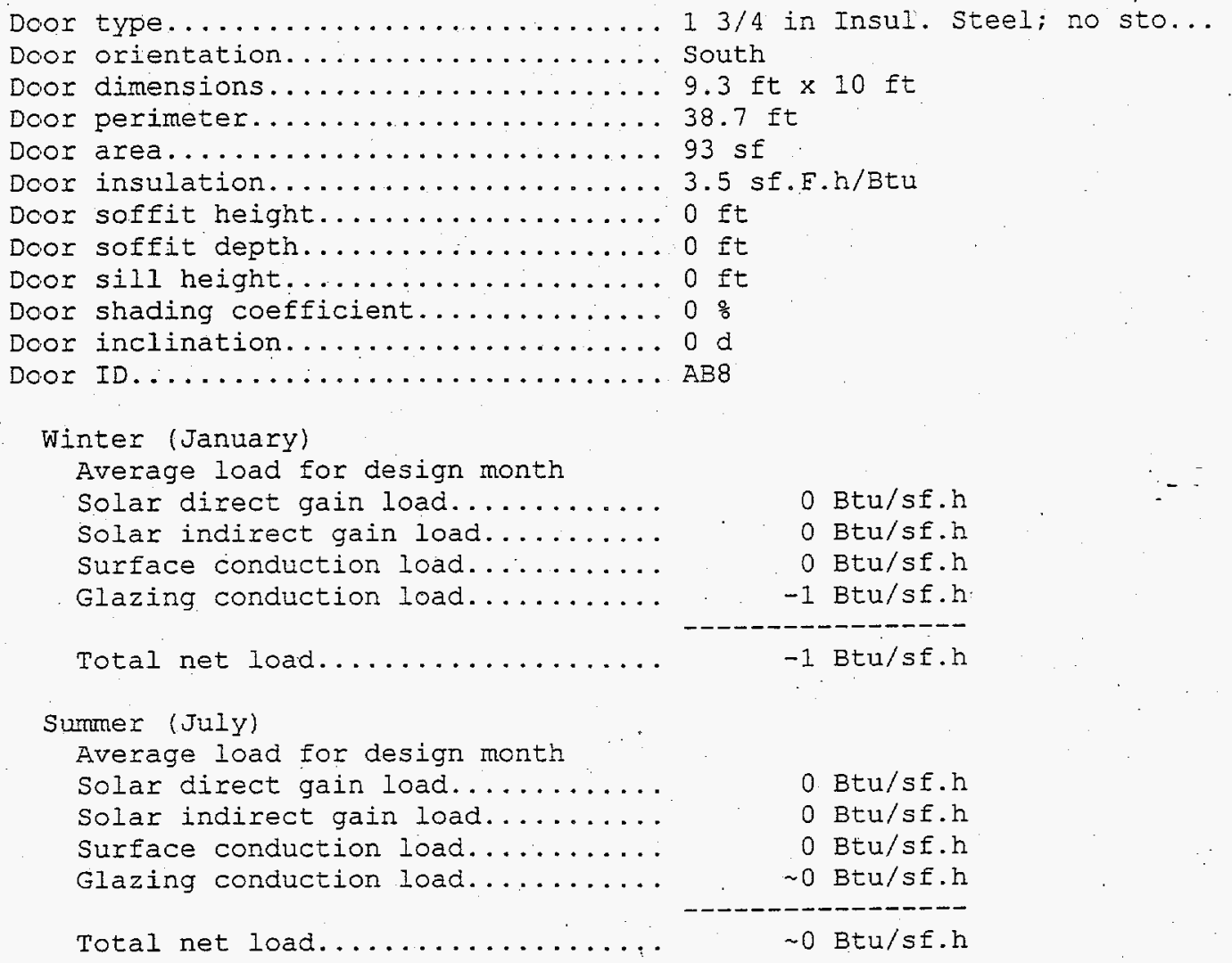




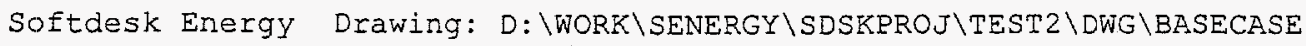
APPENDIX A - LOADS BY BUIIDING ELEMENT (continued)

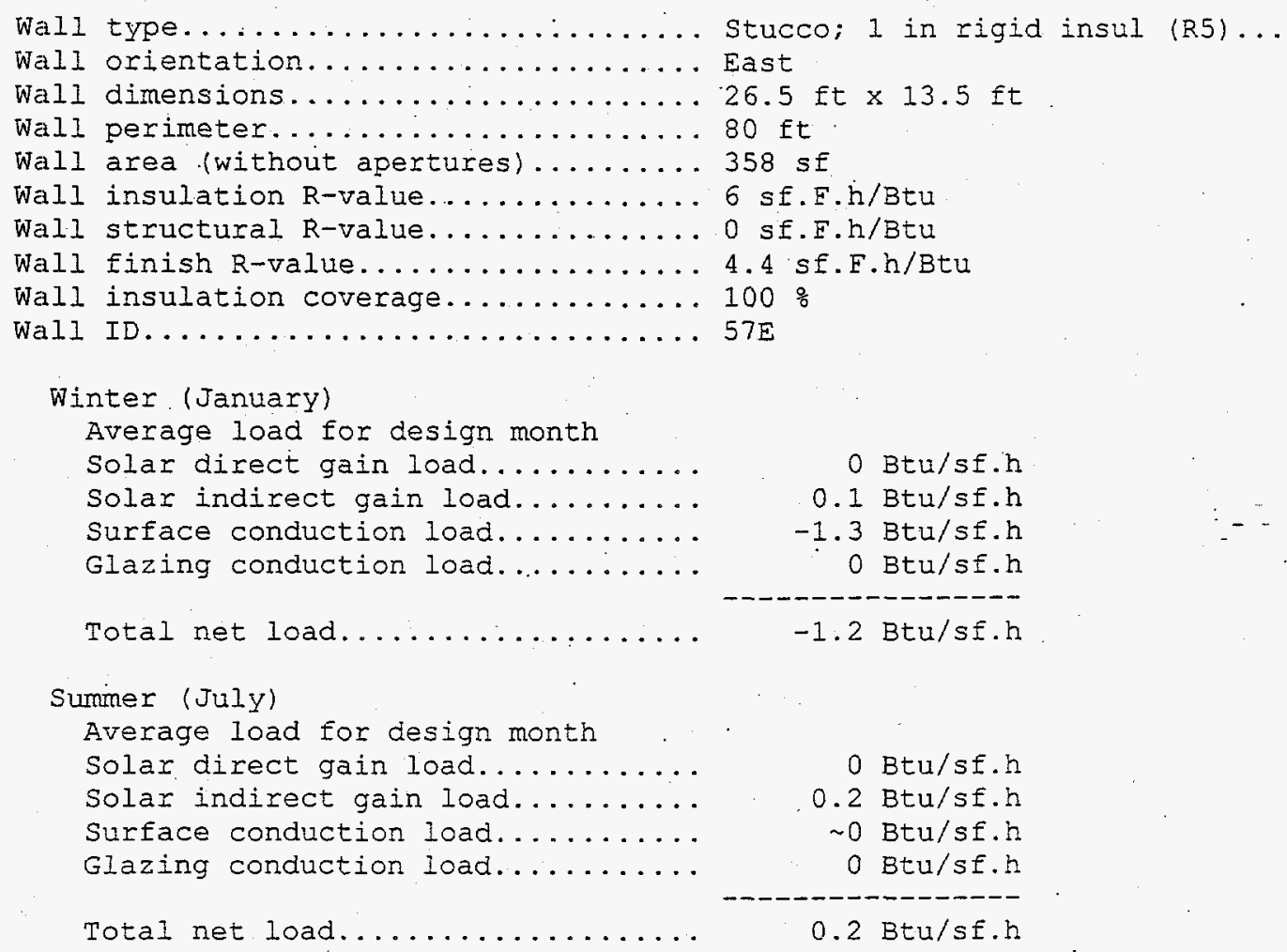




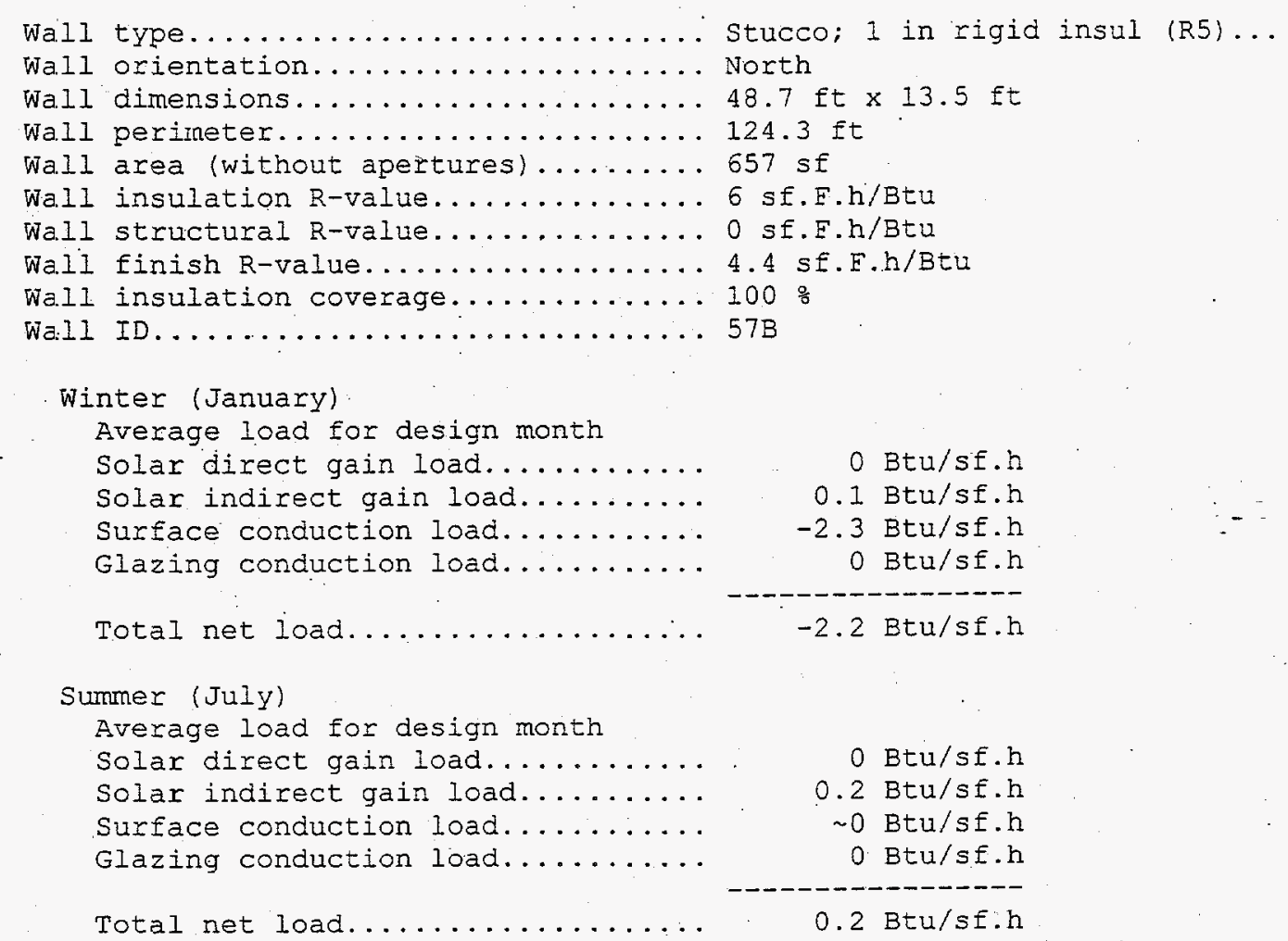




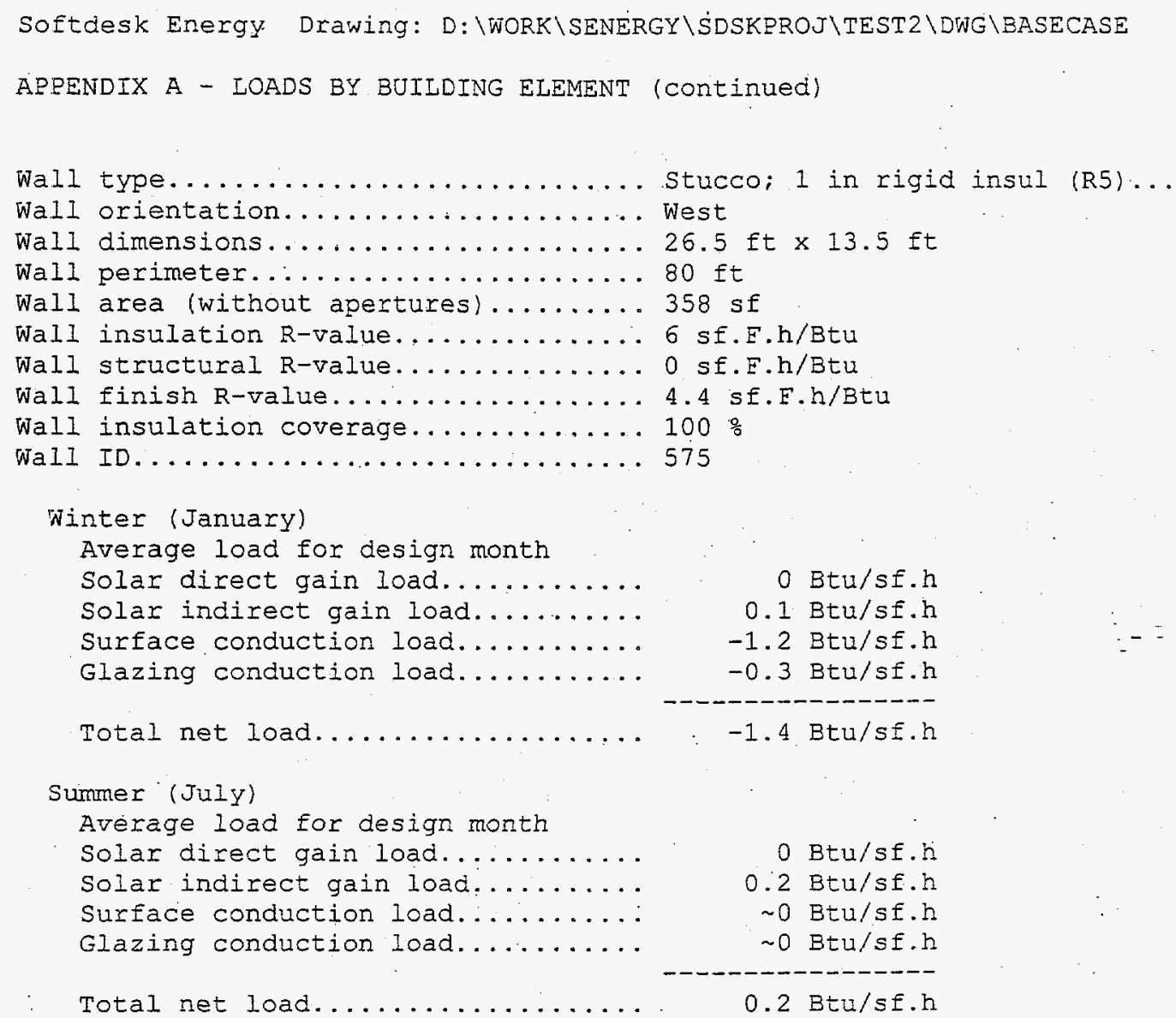




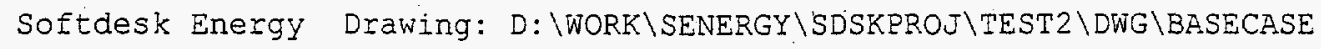

APRENDIX A - LOADS BY BUILDING EEEMENT (continued)

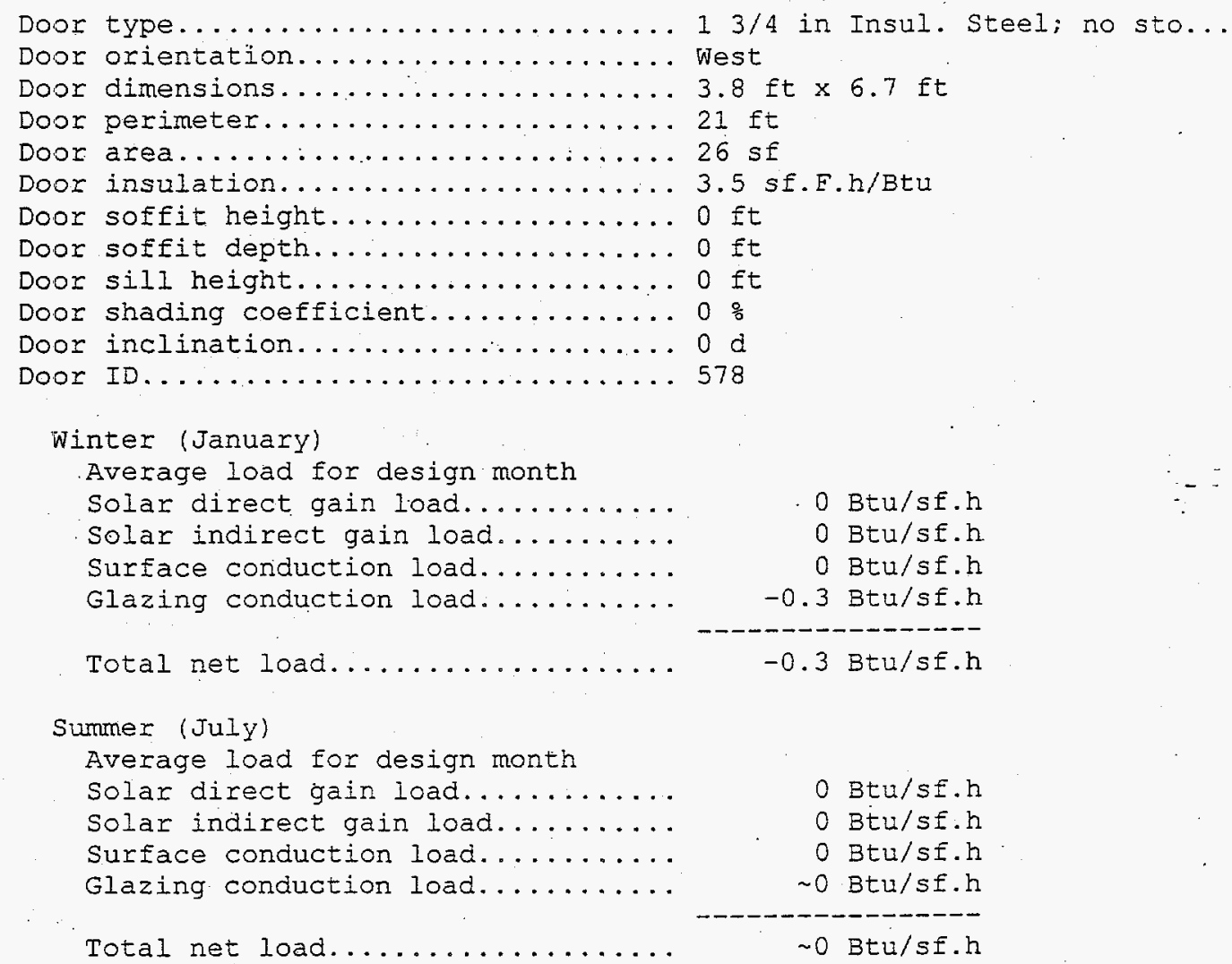




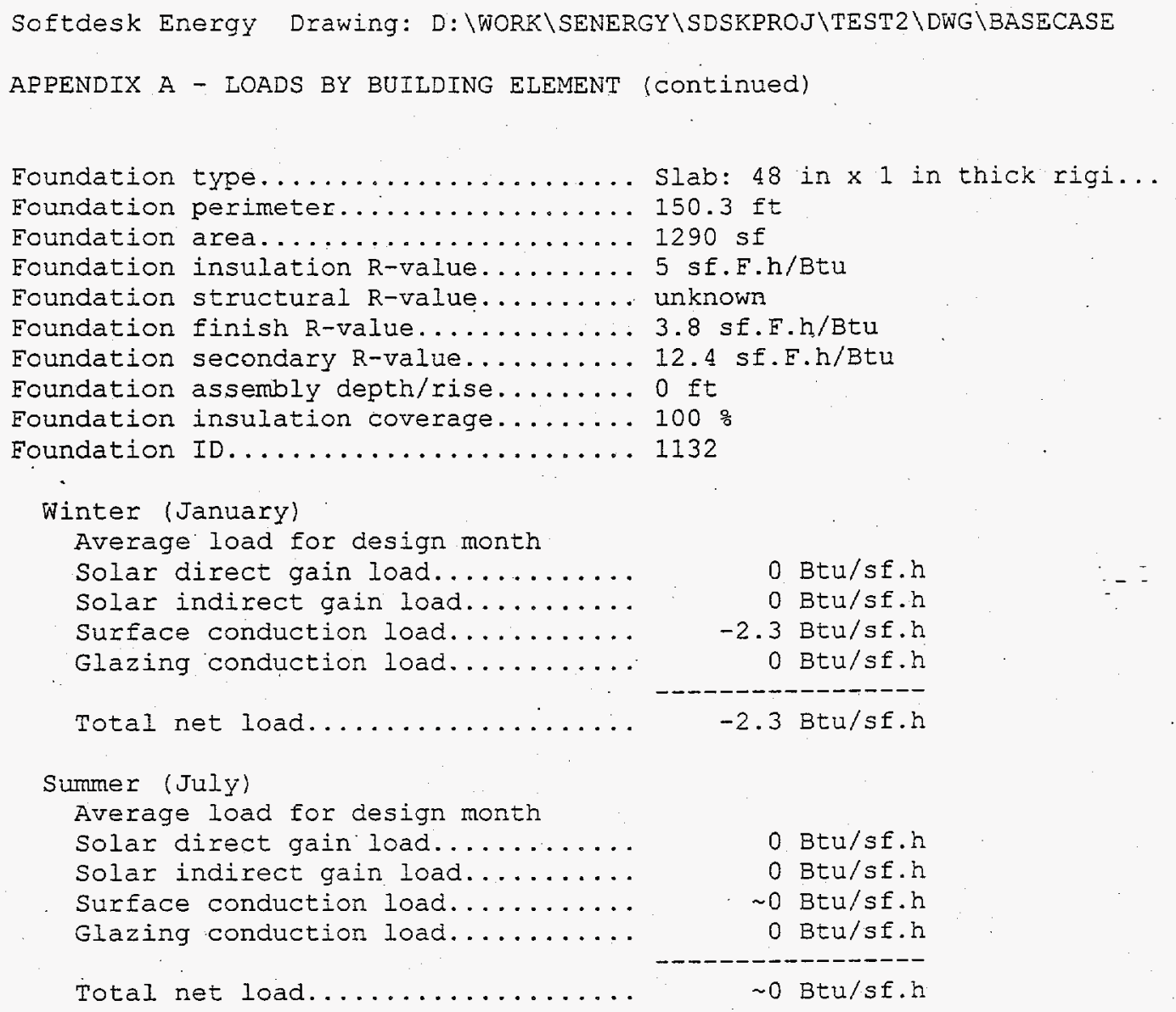




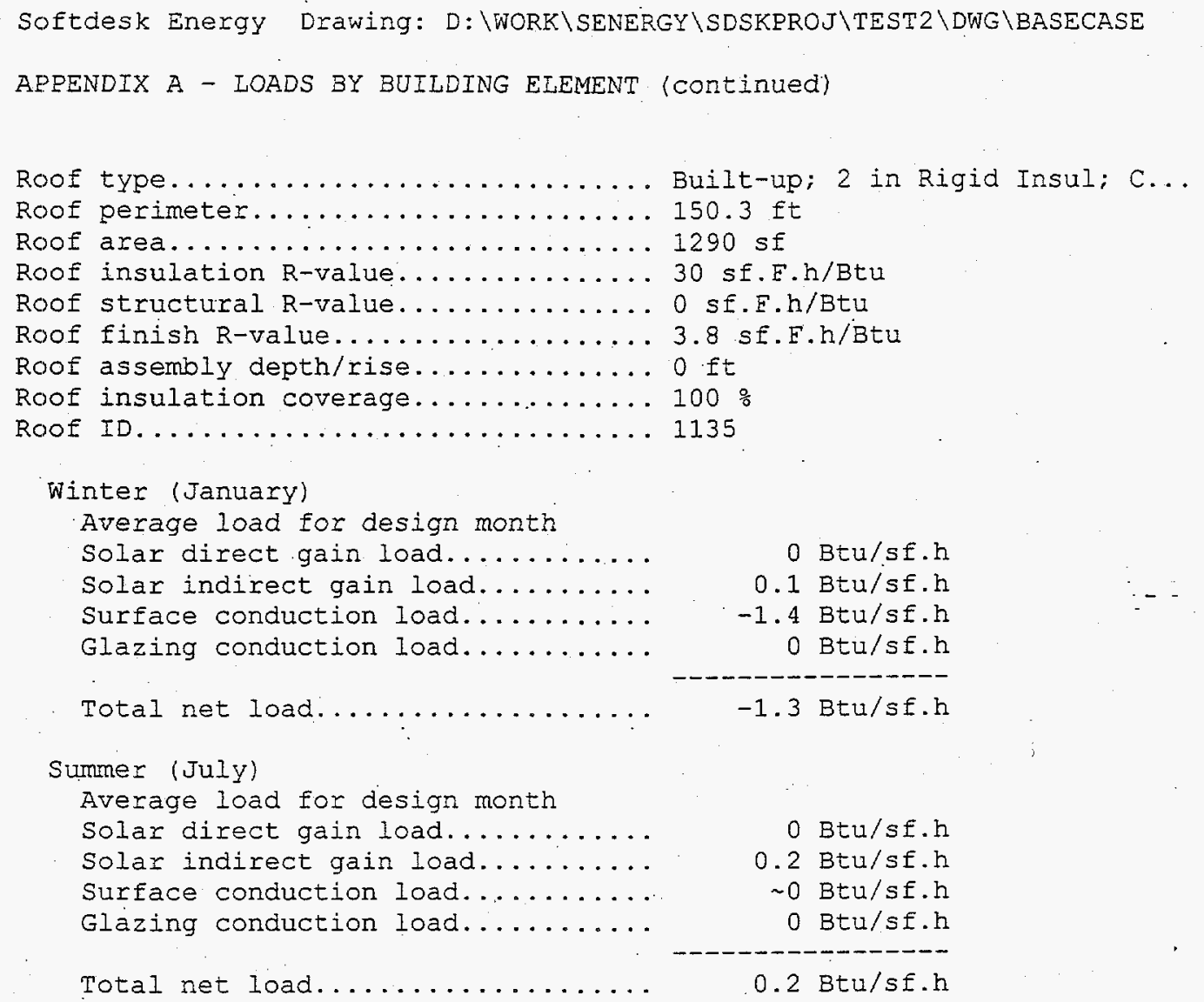




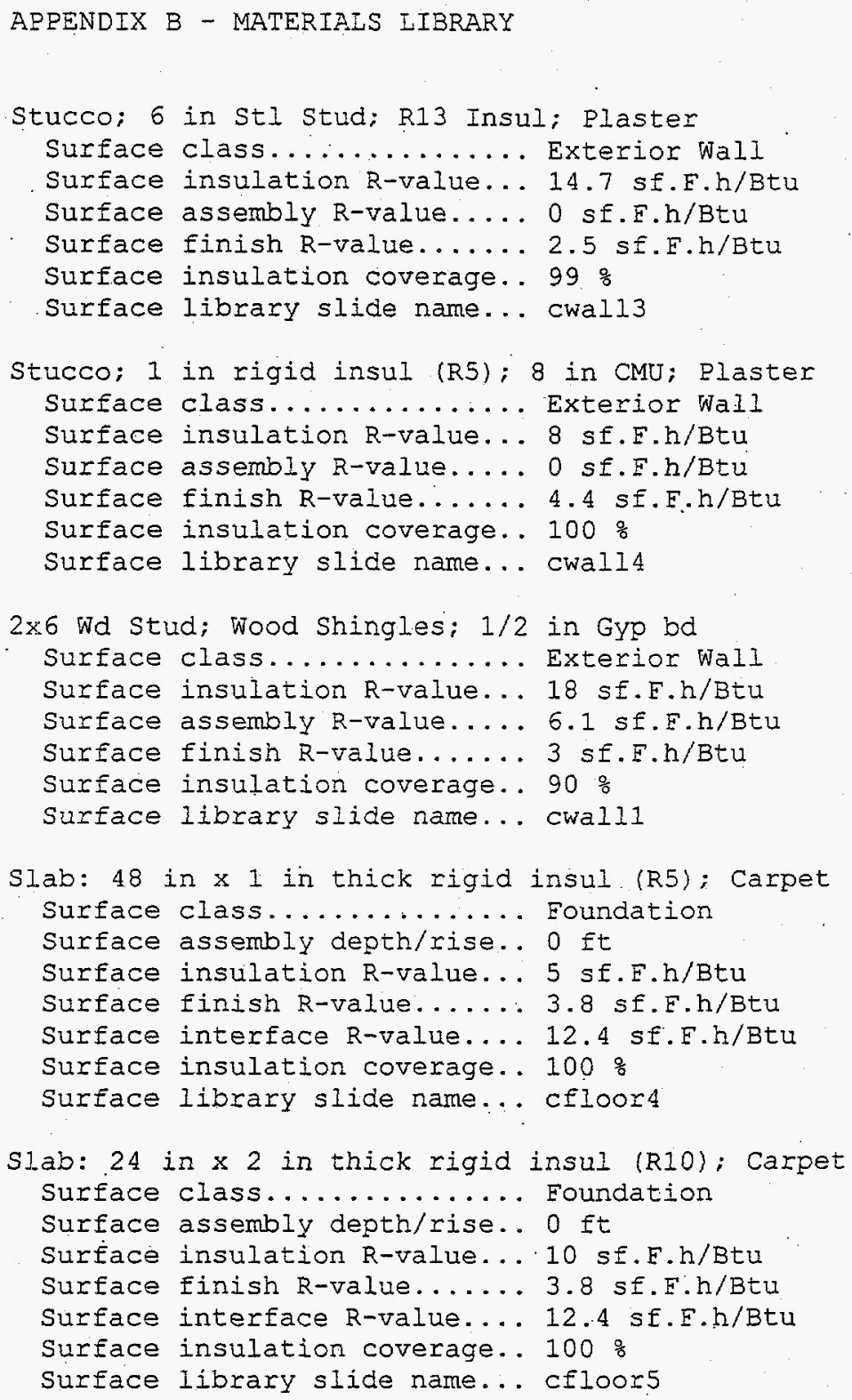




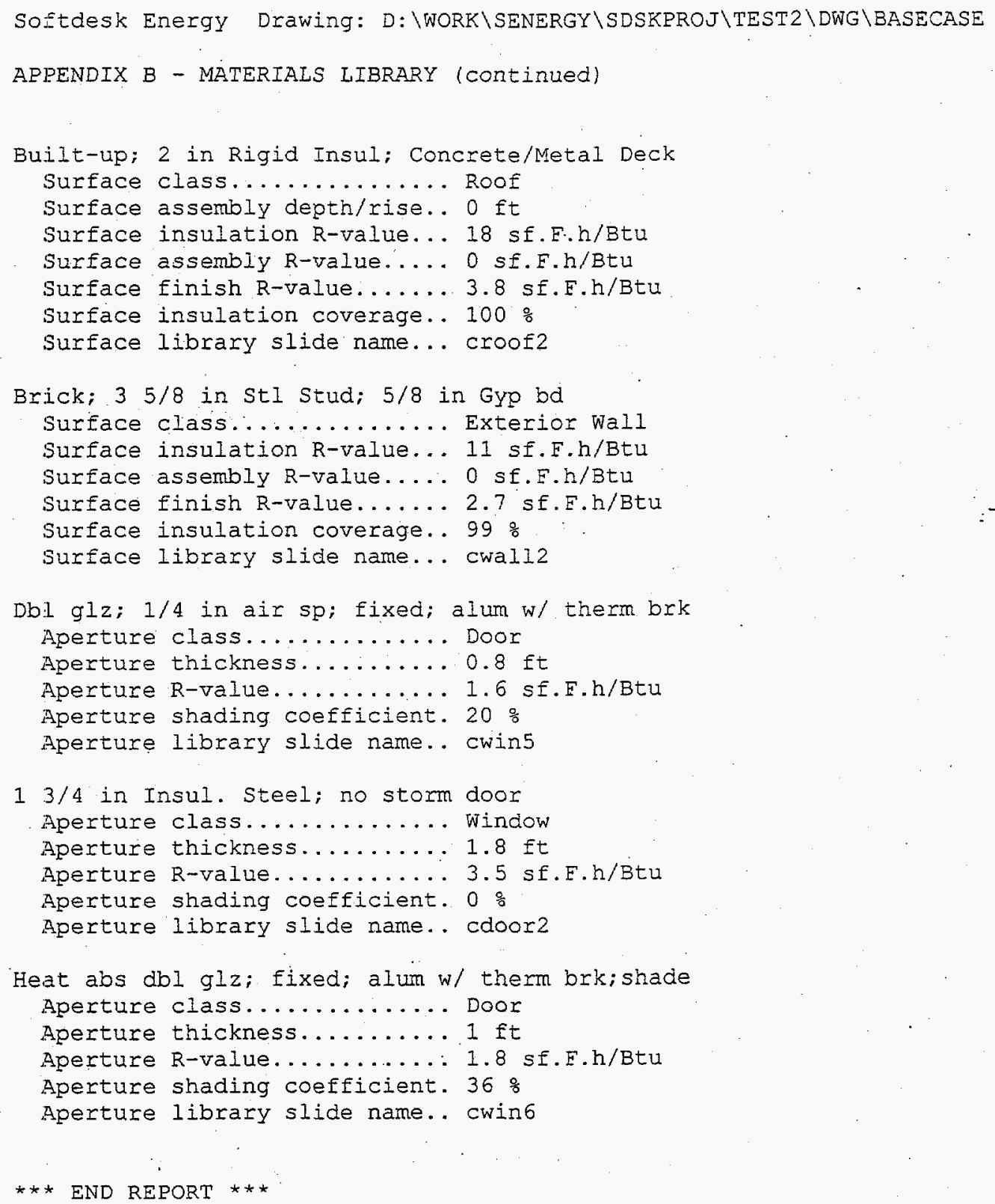




\section{INDEX}

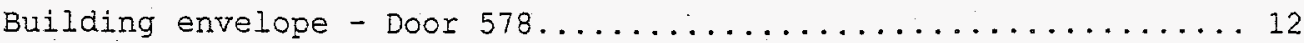

Building envelope - Door AB8....................... 8

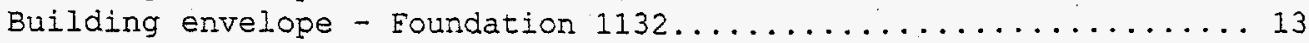

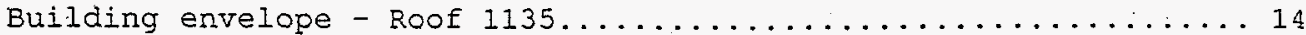

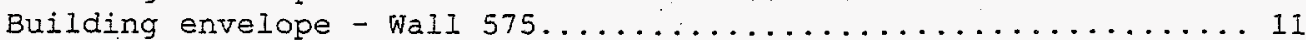

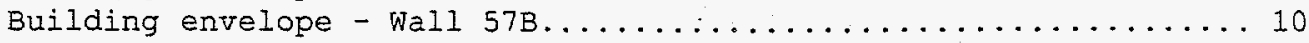

Building envelope - Wall $57 \mathrm{E} \ldots \ldots \ldots \ldots \ldots \ldots \ldots \ldots \ldots \ldots \ldots \ldots$

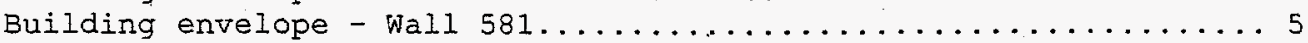

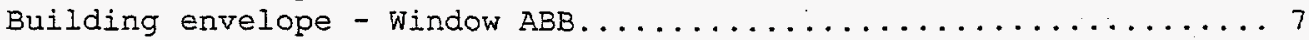

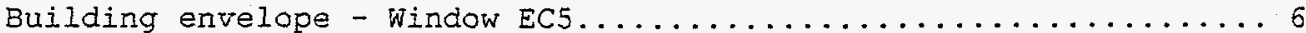

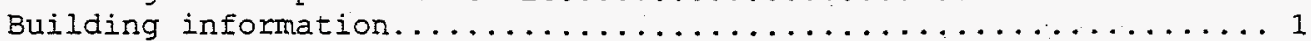

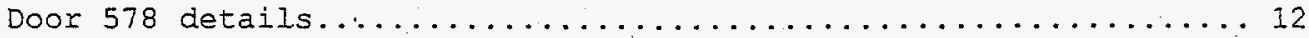

Door AB8 details...........................

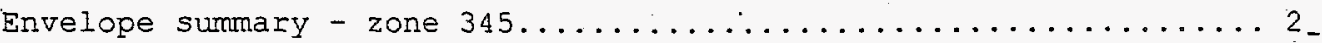

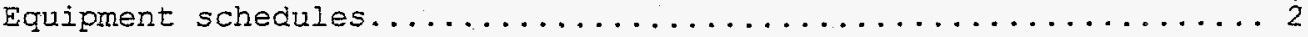

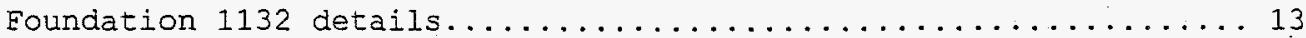

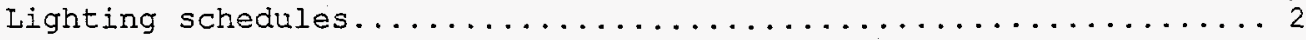

Loads information by building element................... 4

Loads information by envelope element................. 5

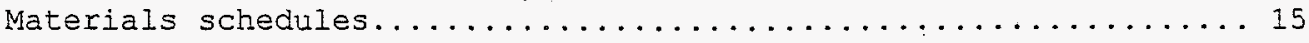

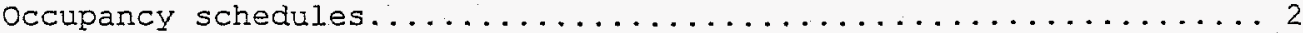

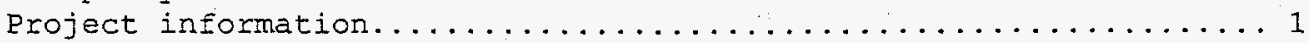

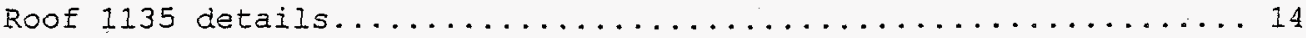

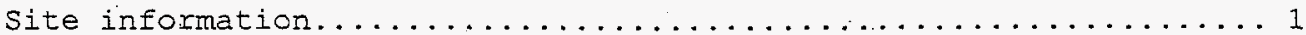

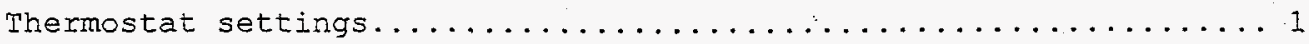

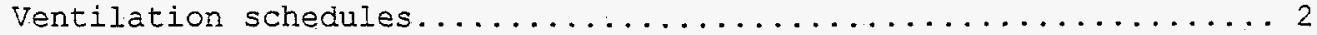

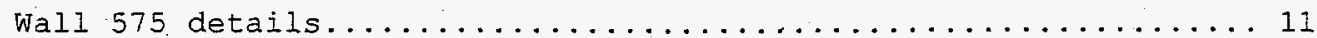

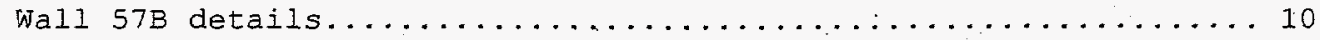

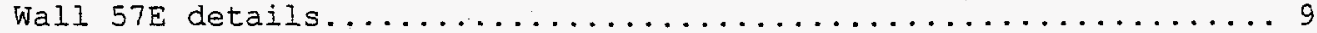

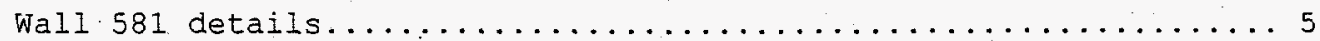

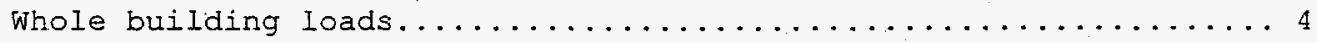

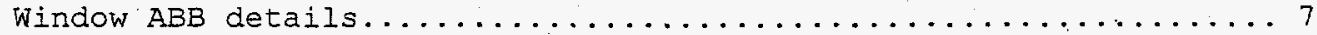

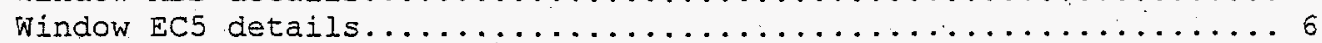




\section{Appendix B: DOE-2.1E Simulation Details}

\section{Base Case}

In order to assess the trend of variation in loads predicted by Softdesk Energy, detailed analysis of the above three scenarios were simulated using DOE 2.1E. The DOE 2.1E model closely represents the Softdesk Energy model. The DOE2 base case input file is attached as Appendix A. The DOE2 model differs from the Softdesk model in the following ways.

1) The floor is modeled as a slab with a U-value of $0.12 \mathrm{BTU} / \mathrm{hr}-\mathrm{ft}^{2}-{ }^{\circ} \mathrm{F}$ in DOE2 and as a slab with R-5 vertical insulation in the Softdesk model.

2) The windows are modeled as double pane, conductivity of $0.56 \mathrm{BTU} / \mathrm{hr}-\mathrm{ft}^{2}-{ }^{\circ} \mathrm{F}$ and shading coefficient of 0.81 in DOE2.

3) The lighting load is $2.4 \mathrm{~W} / \mathrm{ft}^{2}$ for all hours in DOE2.

4) The inside temperature for DOE2 calculations is $72{ }^{\circ} \mathrm{F}$ at all times, for Softdesk it is $65^{\circ} \mathrm{F}$ in winter and $78^{\circ} \mathrm{F}$ in summer.

5) Plug loads are $0.25 \mathrm{~W} / \mathrm{ft}^{2}$, all hours in the DOE2 model.

6) Ventilation is modeled as infiltration at the rate of $72.55 \mathrm{CFM}(0.25 \mathrm{ACH})$ in DOE2.

7) The occupancy load of 1.5 people all hours (215 BTU/hr sensible, $150 \mathrm{BTU} / \mathrm{hr}$ latent) is used in DOE2.

8) The front door is modeled as steel with $\mathrm{U}$-value of $0.28 \mathrm{BTU} / \mathrm{hr}-\mathrm{ft}^{2}-{ }^{\circ} \mathrm{F}$ in DOE2.

\section{Parametric Analysis}

For the three parametric simulations, the following changes were made to the DOE2 in put file.

Scenario 1: Insulation - Improve the thermal resistance of exterior wall sheathings from R-6 to $R-10$ and roof insulation from $R-30$ to $R-45$.

Scenario 2: Windows - Increase the glazing area from $120 \mathrm{ft}^{2}$ to $240 \mathrm{ft}^{2}$ by adding windows to the west and north walls.

Scenario 3: Lighting - Decrease the lighting power from $3.3 \mathrm{~W} / \mathrm{ft}^{2}$ to $2.3 \mathrm{~W} / \mathrm{ft}^{2}$.

\section{DOE2 Output Processing}

The output from DOE2 is in monthly loads (BTU). The loads were divided by the number of hours in the month and the building square footage $\left(1289.8 \mathrm{ft}^{2}\right)$ for comparison with Softdesk.

Post processing file: data extraction from DOE-2e, then data conversion to avg. peak load for the month for Jan. \& July, then print output in format for comparison with Softdesk.

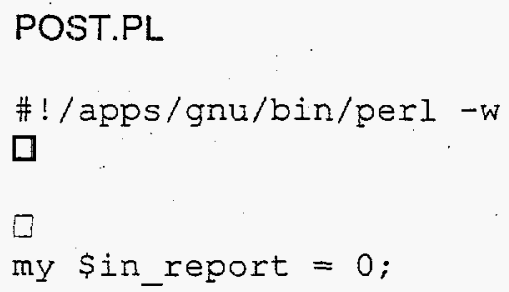




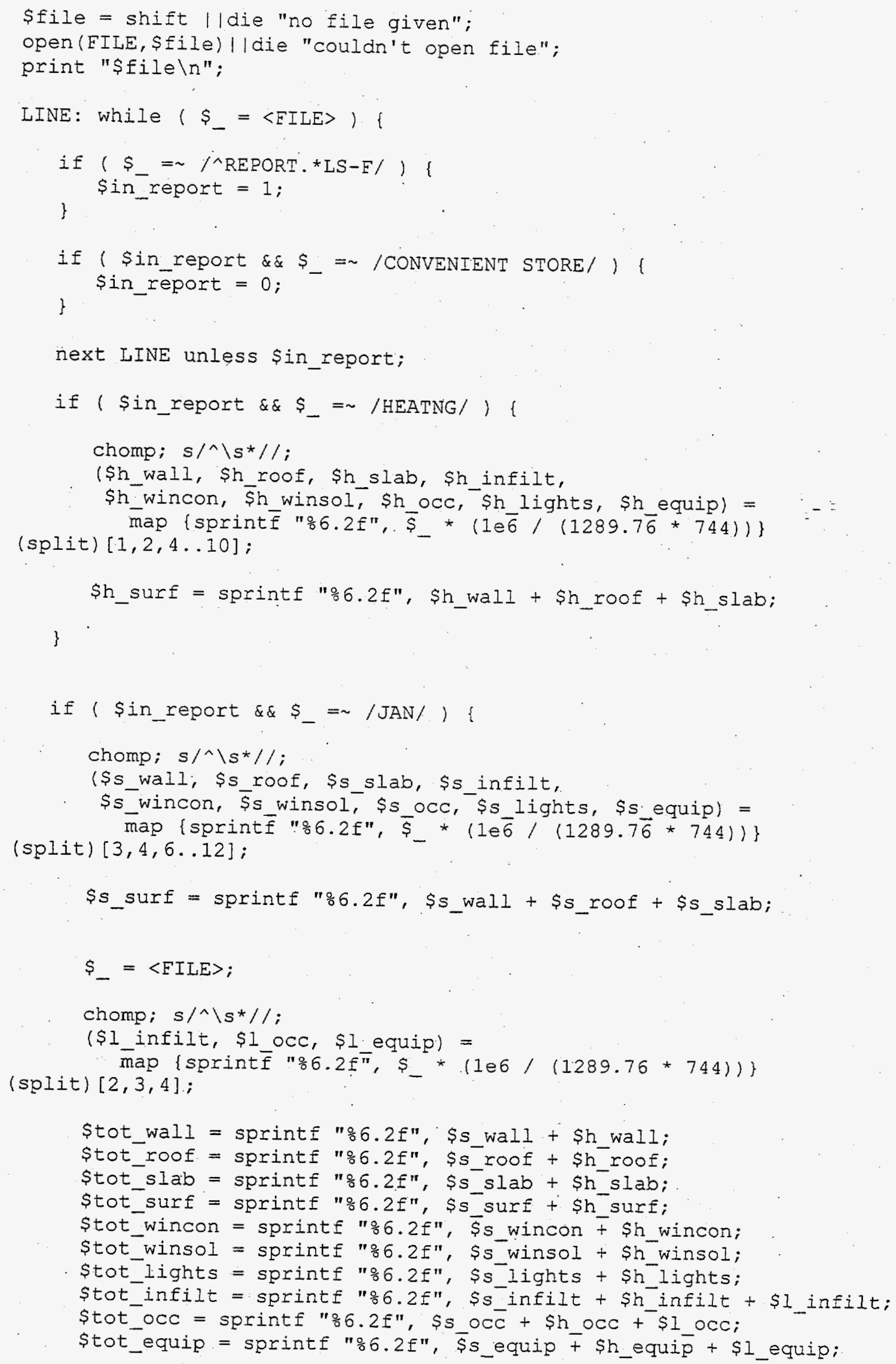




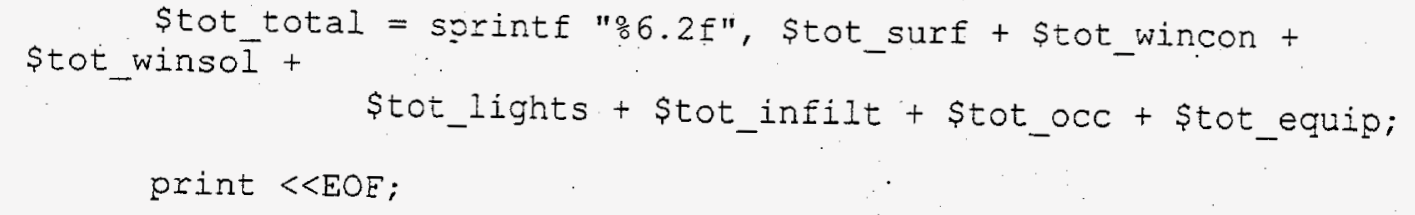




$\begin{array}{ll}\text { Solar gains: } & \text { \$tot_winsol } \\ \text { Surface conduction: } & \text { Stot_surf } \\ \text { Wall Stot_wall } & \\ \text { Roof Stot_roof } & \\ \text { Slab Stot_slab } & \\ \text { Glazing conduction: } & \text { \$tot_wincon } \\ \text { Occupant load: } & \text { \$tot_occ } \\ \text { Equipment load: } & \text { \$tot_equip } \\ \text { Lighting load: } & \text { \$tot_lights } \\ \text { Infiltration load: } & \text { \$tot_infilt } \\ \text { Total. } & \\ \text { EOE } & \\ \text { Stot_total }\end{array}$


Appendix C: DOE-2.1E Input File

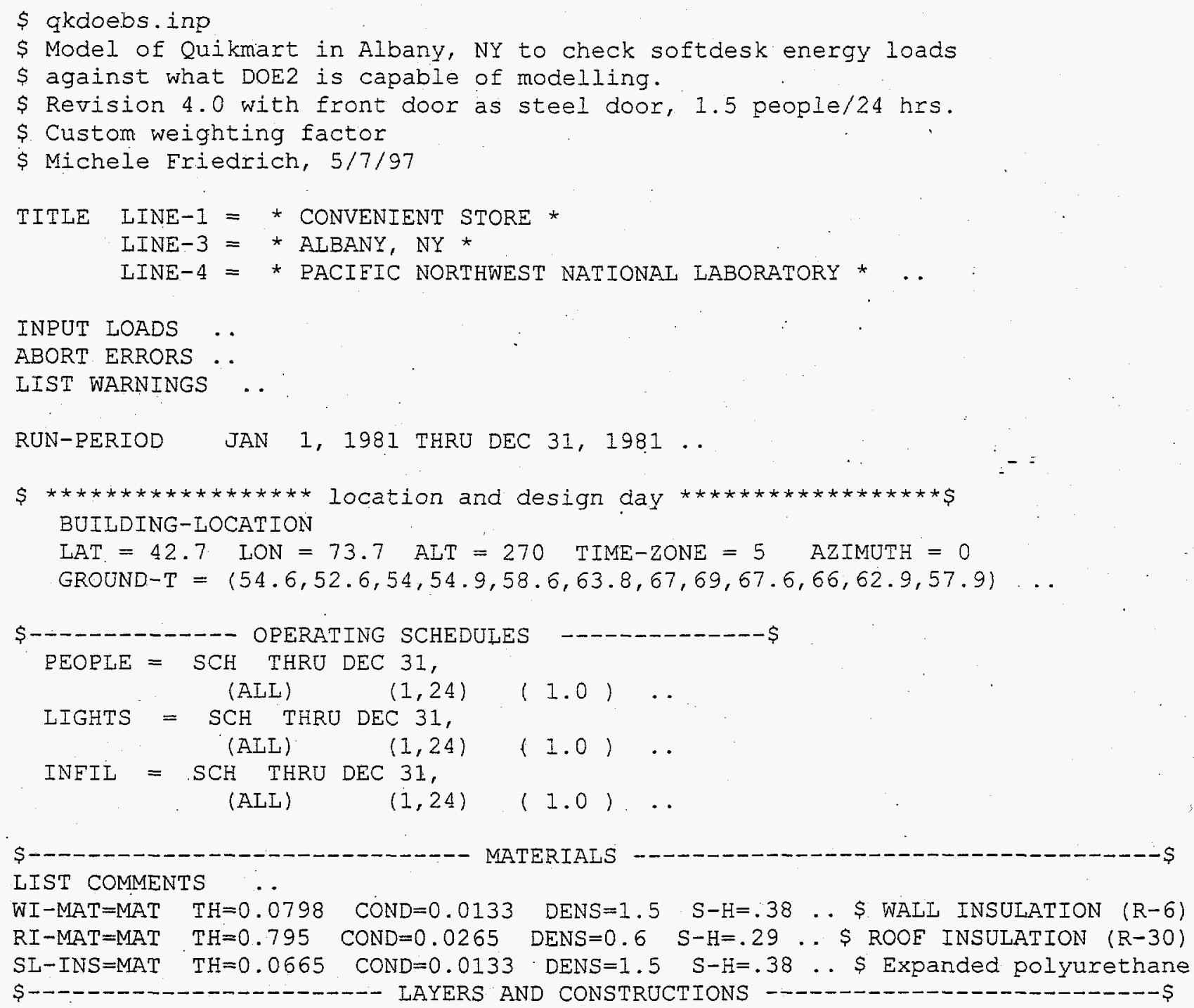

\$ 3/4" STUCCO, 3/4" PLYWOOD, 8-INCH CONC, INSULATION BATTS, PLASTER EXTWALLL=LAYERS $I-E-R=0.68 \quad \mathrm{MAT}=(\mathrm{SC01}, \mathrm{PW05}, \mathrm{CB} 51, \mathrm{WI}-\mathrm{MAT}, \mathrm{GPO} 1) \ldots$

\$ CARPET, 4" R.W. CONCRETE DECK, INSULATION $S L A B I=$ LAYERS $I-F-R=0.76 \quad \mathrm{MAT}=($ SL-INS, CC16, CPO1) $\ldots$ 


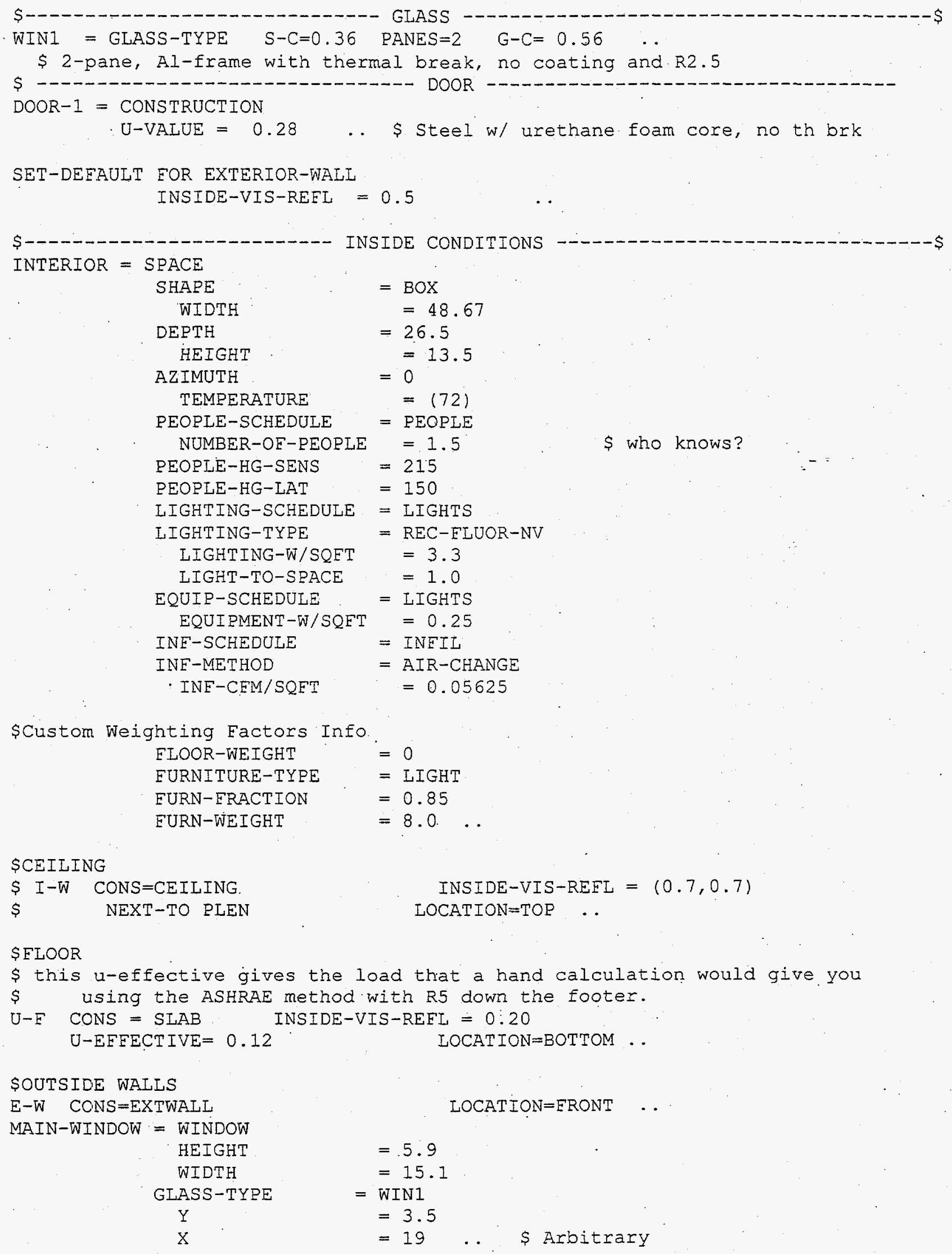




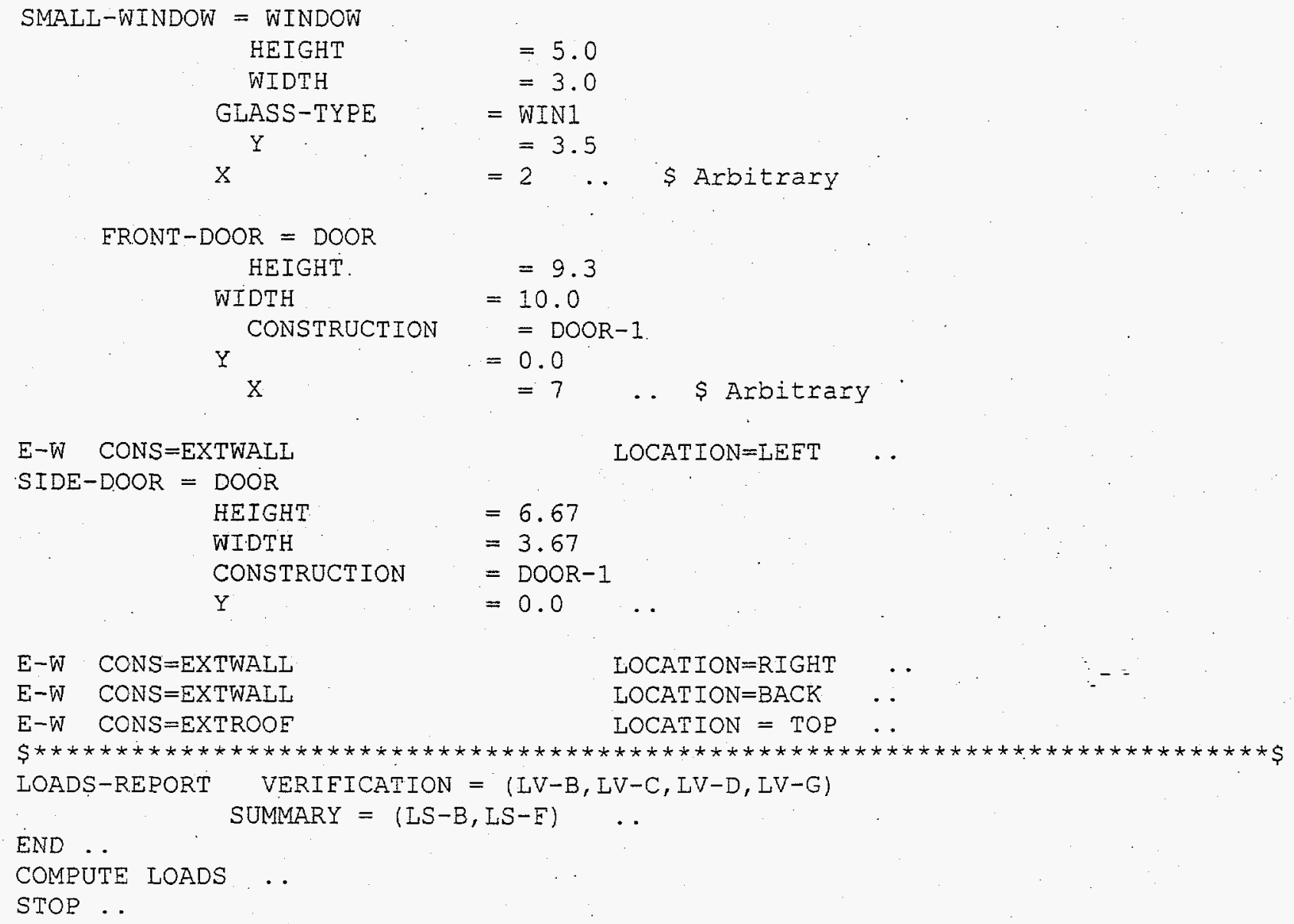

